\title{
The pentapeptide Gly-Thr-Gly-Lys-Thr confers sensitivity to anti-cancer drugs by inhibition of CAGE binding to GSK3 $\beta$ and decreasing the expression of cyclinD1
}

\author{
Youngmi Kim ${ }^{1, *}$, Hyuna Kim ${ }^{1, *}$, Deokbum Park ${ }^{1}$, Hansoo Lee², Yun Sil Lee ${ }^{3}$, Jongseon \\ Choe $^{4}$, Young Myeong Kim ${ }^{4}$, Doyong Jeon ${ }^{5}$, Dooil Jeoung ${ }^{1}$ \\ ${ }^{1}$ Department of Biochemistry, College of Natural Sciences, Kangwon National University, Chunchon 24341, Korea \\ ${ }^{2}$ Department of Biological Sciences, College of Natural Sciences, Kangwon National University, Chunchon 24341, Korea \\ ${ }^{3}$ College of Pharmacy, Ewha Womans University, Seoul 03760, Korea \\ ${ }^{4}$ Graduate School of Medicine, Kangwon National University, Chunchon 24341, Korea \\ ${ }^{5}$ L-Base Company, Seoul 01062, Korea \\ *These authors contributed equally to this work \\ Correspondence to: Dooil Jeoung, email: jeoungd@kangwon.ac.kr
}

Keywords: anti-cancer drug-resistance, CAGE, cyclinD1, GSK3 $\beta$, peptides

Received: February 12, $2016 \quad$ Accepted: January 03, $2017 \quad$ Published: January 13, 2017

\section{ABSTRACT}

We previously reported the role of cancer/testis antigen CAGE in the response to anti-cancer drugs. CAGE increased the expression of cyclinD1, and pGSK3 $\beta^{\text {ser9, }}$, an inactive GSK3 $\beta$, while decreasing the expression of phospho-cyclinD1Thr ${ }^{286}$. CAGE showed binding to GSK3 $\beta$ and the domain of CAGE (amino acids 231-300) necessary for binding to GSK3 $\beta$ and for the expression regulation of cyclinD1 was determined. ${ }^{269}{ }^{6 T G K T}{ }^{273}$ peptide, corresponding to the DEAD box helicase domain of CAGE, decreased the expression of cyclinD1 and pGSK3 $\beta^{\text {ser9 }}$ while increasing the expression of phosphocyclinD1 ${ }^{\text {Thr286. }}$. GTGKT peptide showed the binding to CAGE and prevented CAGE from binding to GSK3 $\beta$. GTGKT peptide changed the localization of CAGE and inhibited the binding of CAGE to the promoter sequences of cyclin D1. GTGKT peptide enhanced the apoptotic effects of anti-cancer drugs and decreased the migration, invasion, angiogenic, tumorigenic and metastatic potential of anti-cancer drug-resistant cancer cells. We found that Lys ${ }^{272}$ of GTGKT peptide was necessary for conferring anti-cancer activity. Peptides corresponding to the DEAD box helicase domain of CAGE, such as AQTGTGKT, QTGTGKT and TGTGKT, also showed anti-cancer activity by preventing CAGE from binding to GSK3 $\beta$. GTGKT peptide showed ex vivo tumor homing potential. Thus, peptides corresponding to the DEAD box helicase domain of CAGE can be developed as anti-cancer drugs in cancer patients expressing CAGE.

\section{INTRODUCTION}

CAGE, a cancer/testis gene, was isolated by the screening of recombinant cDNA expression libraries using the sera of patients with gastric cancers [1]. A positive rate of anti-CAGE antibody in 7 of 13 (53.8\%) patients with microsatellite instability-positive endometrial cancer and in 1 of 3 patients with atypical endometrial hyperplasia [2] suggests that CAGE can be useful for prognosis or early diagnosis of patients with microsatellite instability- positive endometrial cancers. The methylation of CAGE promoter sequences in premalignant lesions suggests that the expression status of CAGE can be a useful diagnostic marker for early detection of cancer [3]. CAGE promotes cell motility by activating extracellular signal-regulated kinase (ERK) and p38 MAPK [4].

CAGE displays oncogenic potential and enhances cellular proliferation by increasing the expression of cyclinD1 via AP-1 [5]. CAGE, through binding to HDAC2, represses the expression of P53 to confer resistance to anti- 
cancer drugs [6]. miR-200b decreases the expression of cyclinD1 and myosin heavy chain (MHC) [7]. miR-200b confers sensitivity to anti-cancer drugs by decreasing the expression of CAGE [8].

The inhibition of GSK3 $\beta$ ameliorates cisplatininduced cytotoxicity [9]. The activation of GSK3 $\beta$ increases the phosphorylation of RNPC1 and the expression of $\mathrm{p} 53$ [10]. The inactivation of GSK3 $\beta$ leads to the accumulation of mutant p53 [11]. GSK $3 \beta$ suppresses breast carcinogenesis in a manner associated with its effect on the phosphorylation, ubiquitination and the stability of progesterone receptor A [12]. Over-expression of inactive GSK $3 \beta$ inhibits JNK activation, resulting in a suppression of apoptosis by quercetin [13]. GSK3 $\beta$ enhances growth suppression by directly phosphorylating KLF-6 [14]. The mechanisms of radioprotection by GSK3 $\beta$ inhibitors in hippocampal neurons involve the regulation of p53 accumulation [15].

DIF-1 inhibits the growth of HCT-116- and HeLaxenograft tumors together with decreasing phosphorylation level of GSK $3 \beta^{\text {Ser9 }}$ and also suppresses the expressions of cyclinD1 [16]. mTORC2 blockade is responsible for reduction of cyclinD 1 by GSK3 $\beta$ [17]. Inactive GSK3 $\beta$ attenuates proteasomal degradation of cyclinD1 by reducing phospho-cyclinD1 $1^{\text {Thr286 }}$ levels [18]. Inactive GSK $3 \beta$ increases cyclinD1 gene transcription by increasing its transcription factor $\beta$-catenin in the nucleus [18].

NF- $\kappa \mathrm{B}$-activating selectable peptides (NASPs), when co-expressed with oncogenic Ras (H-Ras (V12)), allows rodent fibroblasts to overcome senescence and acquire a transformed tumorigenic phenotype [19]. Tumor homing and penetrating peptide iRGD enhances the effect of paclitaxel-loaded PEG-PLA nanoparticles (MT1-NP-PTX) on glioblastoma [20]. Angiotensin-(1-7) [Ang-(1-7)], an endogenous heptapeptide hormone of the renin-angiotensin system displays anti-tumor activity [21]. VEGFR-3 inhibiting peptides display anti-oncogenic activity [22]. The heptapeptide of the PKC delta-V5 region sensitizes human cancer cells through its binding to HSP27 [23]. Inherbin3, a peptide antagonist of ErbB1 receptor, inhibits EGF-induced ErbB1 phosphorylation, cell growth, and migration in two human tumor cell lines [24]. These reports suggest that peptides originating from proteins can be employed as anti-cancer drugs.

We were interested to examine the mechanism of anti-cancer drug-resistance conferred by CAGE.We present evidence that CAGE confers anti-cancer drugresistance by binding to GSK $3 \beta$ and increasing the expression of cyclin D1 and pGSK $3 \beta^{\text {Ser9 }}$. We show anticancer activity of peptides corresponding to the DEAD box helicase domain of CAGE and the mechanisms of anti-cancer drug sensitivity conferred by these peptides. Thus, peptides corresponding to the DEAD box helicase domain of CAGE can be developed as anti-cancer drugs for the treatment of cancer patients expressing CAGE.

\section{RESULTS}

\section{CAGE increases the expression of cyclin D1 and pGSK3 ${ }^{\text {Ser9 }}$ while decreasing the expression of phospho-cyclinD1 ${ }^{\text {Thr286 }}$}

CAGE increases the expression of cyclinD1 via AP-1 and E2F [5]. We first investigated the mechanisms involved in the expression regulation of cyclinD1 by CAGE. Anti-cancer drug-resistant cancer cell lines, such as $\mathrm{SNU} 387^{\mathrm{R}}$ and Malme $3 \mathrm{M}^{\mathrm{R}}$ cell lines, showed higher expression level of CAGE than their sensitive counterparts (Supplementary Figure 1A). Meljuso and Hep3B cell lines that do not express CAGE did not show the expression of cyclinD1 (Supplementary Figure 1A). The expression level of CAGE showed an inverse relationship with the expression level of phospho-cyclinD1 ${ }^{\text {Thr286 }}$ and pGSK3 $\beta^{\text {Tyr216, }}$ an active form of GSK3 $\beta$ (Supplementary Figure 1A). Immunofluorescence staining showed mostly nuclear localization of phospho-cyclinD1 $1^{\mathrm{Th} 286}$ in Malme3M cells, but not in Malme $3 \mathrm{M}^{\mathrm{R}}$ cells (Supplementary Figure 1B). Phosphorylation of GSK $3 \beta$ at Ser9 leads to the increased expression of cyclinD1 [18]. Because the expression level of CAGE showed correlation with that of cyclinD1 (Supplementary Figure 1A), we examined the effect of CAGE on the expression of pGSK $3 \beta^{\text {Ser9 }}$, an inactive GSK3 $\beta$. The down-regulation of CAGE decreased the expression of cyclinD1 and pGSK $3 \beta^{\text {Ser9 }}$ while increasing the expression of phospho-cyclinD1 ${ }^{\text {Thr286 }}$ (Supplementary Figure 1C). Immunofluorescence staining confirmed the effect of the down-regulation of CAGE on the expression of pGSK $3 \beta^{\text {Ser9 }}$ and phospho-cyclinD1 $1^{\text {Thr286 }}$ (Supplementary Figure 1D). CAGE showed the localization in both nucleus and cytoplasm in Malme $3 \mathrm{M}^{\mathrm{R}}$ cells (Supplementary Figure 1D). These results suggest that CAGE increases the expression cyclinD1 in association with its effect on the phosphorylation of GSK3 $\beta$.

\section{GSK3ß-cyclinD1 axis functions downstream of CAGE}

We next examined the relationship between GSK3 $\beta$ and the expression of cyclinD1. The inactivation of GSK $3 \beta$ by $\mathrm{LiCl}$ increased the expression of $\mathrm{pGSK} 3 \beta^{\mathrm{Ser} 9}$ and cyclinD1 while decreasing the expression of phospho-cyclinD1 ${ }^{\text {Thr286 }}$ in SNU387 and Malme3M cells (Supplementary Figure 2A). However, LiCl did not change the expression level of CAGE (Supplementary Figure 2A). The down-regulation of cyclinD1 did not change the expression of CAGE, phospho-cyclinD1 $1^{\text {Thr286 }}$ or pGSK3 $\beta^{\text {Ser9 }}$ in $\mathrm{SNU}_{387^{\mathrm{R}}}$ or Malme $3 \mathrm{M}^{\mathrm{R}}$ cells (Supplementary Figure 2B). This suggests that cyclinD1 functions downstream of GSK3 $\beta$. The down-regulation of cyclinD1 enhanced cleavage of PARP and FAK in response to taxol in Malme $3 \mathrm{M}^{\mathrm{R}}$ cells (Supplementary 
Figure 2C). The down-regulation of cyclinD1 enhanced sensitivity to taxol in Malme $3 \mathrm{M}^{\mathrm{R}}$ cells (Supplementary Figure 2D). Because CAGE the expression of pGSK3 $\beta^{\text {Ser9 }}$ (Supplementary Figure 1C), we examined the possibility of the binding of CAGE to GSK3 $\beta$. The expression of pGSK3 $3 \beta^{\text {Tyr216 }}$, active form of GSK3 $\beta$, was lower in Malme $3 \mathrm{M}^{\mathrm{R}}$ cells than in Malme $3 \mathrm{M}$ cells (Supplementary Figure 2E). CAGE showed binding to GSK3 $\beta$ in SNU38 ${ }^{R}$ (data now shown) and Malme $3 \mathrm{M}^{\mathrm{R}}$ cells (Supplementary Figure 2E). CAGE showed a co-localization with GSK3 $\beta$ in SNU387 ${ }^{\mathrm{R}}$ (Supplementary Figure $2 \mathrm{~F}$ ) and Malme $3 \mathrm{M}^{\mathrm{R}}$ cells (data not shown). It remains to be seen whether CAGE exerts a direct regulation on GSK3 $\beta$ activity. These results suggest that CAGE confers resistance to anticancer drugs through GSK3 $\beta$-cyclinD1 axis.

\section{CAGE domain encompassing amino acids 231- 300 is necessary for binding of CAGE to GSK3 $\beta$ and for increasing the expression of cyclinD1}

Because CAGE showed binding to GSK3 $\beta$ (Supplementary Figure 2E), we wanted to determine the domain of CAGE that is necessary for binding to GSK3 $\beta$. We hypothesized that this domain would be critical for conferring resistance to anti-cancer drugs. For this, various CAGE deletion constructs were made (Figure 1A). We found that the CAGE domain corresponding to amino acids 231-300 was necessary for increasing the expression of cyclinD1 and binding to GSK3 $\beta$ (Figure 1B). CAGE domain corresponding to amino acids 231-300 was also necessary for conferring resistance to taxol (Figure 1C). CAGE domain (amino acids 231-300) contains ATP-binding site $\left({ }^{269} \mathrm{GTGKT}^{273}\right)$, and database (TumorHOPe) search predicts that GTGKT, SQAWP and RNGPG peptides display tumor homing potential (Figure 1D). TumorHOPe database shows that GTG-containing peptides, such as, CWGTGLC and WGTGLC peptides, display homing potential to mouse melanoma based on phage display. We hypothesized that ATP-binding site of CAGE would be necessary for binding to GSK $3 \beta$ and for increasing the expression of cyclinD1. We introduced point mutation into ATP-binding site of CAGE to examine the importance of ATP-binding site for increasing the expression of cyclinD1 and the binding of CAGE to GSK $3 \beta$. Full-length wild type CAGE (G-T-G-K-T) and mutant CAGE (G-A-G-K-T) increased the expression of cyclinD1 and showed binding to GSK3 $\beta$ in Malme $3 \mathrm{M}$ cells (Figure 1E). However, full-length point mutant CAGEs, such as G-T-G-A-T and G-T-G-K-A, did not increase the expression of cyclinD1 or binding to GSK3 $\beta$ in Malme3M cells (Figure 1E). This suggests the importance of ATPbinding site of CAGE (K272, T273) in the expression of cyclinD1 and the binding of CAGE to GSK3 $\beta$. We wanted to examine the mechanism of the increased expression of cyclinD1 by CAGE. CyclinD1 promoter contains the binding sites for various transcriptional factors such as HDAC2, SNAIL, AP1 and SP1 (Supplementary
Figure $3 \mathrm{~A}$ ). Because cyclinD1 promoter sequences contain binding site for HDAC2, we hypothesized that CAGE would bind to the promoter sequences of cyclinD1 to increase the expression of cyclinD1. Malme3M cells transfected with full-length wild type CAGE or CAGE deletion construct (pFLAG-CAGE ${ }^{\triangle H E L I c}$, pFLAG-CAGE ${ }^{\triangle D E A D c-1}$ or FLAG-CAGE ${ }^{\triangle \mathrm{DEADC}-2}$ ) showed the binding of CAGE to the promoter sequences of cyclinD1 (Supplementary Figure 3B). However, Malme3M cells transfected with $\mathrm{CAGE}^{\mathrm{KH}-1}$ deletion construct did not show the binding of CAGE to the promoter sequences of cyclinD1 (Supplementary Figure 3B). Malme3M cells transfected with full-length wild type CAGE (G-T-G-K-T) or fulllength point mutant CAGE (G-A-G-K-T) showed the binding of CAGE to the promoter sequences of cyclinD1 (Supplementary Figure 3C). However, Malme3M cells transfected with full-length point mutant CAGEs, such as G-T-G-A-T and G-T-G-K-A, did not show the binding of CAGE to the promoter sequences of cyclinD1 (Supplementary Figure 3C). These results suggest that the increased expression of cyclinD1 by CAGE involves the direct binding of CAGE to the promoter sequences of cyclinD1. Full-length mutant CAGEs, such as G-T-G-A-T and G-T-G-K-A, did not confer resistance to anti-cancer drugs in Malme3M cells (Supplementary Figure 4A). Unlike wild type full-length CAGE and mutant CAGE mutant (G-A-G-K-T), full-length mutant CAGEs, such as G-T-G-A-T and G-T-G-K-A, increased caspase-3 activity in response to taxol in Malme3M cells (Supplementary Figure 4B). G-T-G-A-T and G-T-G-K-A mutants induced cleavage of PARP in response to taxol in Malme3M cells (Supplementary Figure 4C). Unlike wild type full-length CAGE and mutant CAGE mutant (G-A-G-K-T), fulllength mutants G-T-G-A-T and G-T-G-K-A did not enhance the migration or invasion potential of Malme3M cells (Supplementary Figure 4D). Malme3M cells transfected with wild type full-length CAGE or mutant CAGE mutant (G-A-G-K-T) showed a higher growth potential than Malme3M cells transfected with full-length mutant G-T-G-A-T or G-T-G-K-A based on colony formation assay (Supplementary Figure 4E). These results suggest that CAGE domain encompassing amino acids 231-300 is necessary for binding to GSK $3 \beta$ and for the increased expression of cyclinD1. These results provide the basis for designing anti-cancer peptides corresponding to the DEAD box helicase domain of CAGE.

\section{GTGKT peptide decreases the expression of cyclinD1, pGSK3 $\beta^{\text {Ser9 }}$ and inhibits the binding of CAGE to GSK3 $\beta$}

${ }^{269} \mathrm{GTGKT}^{273}$ amino acids within the DEAD box domain correspond to the ATP-binding site of CAGE and are predicted to display tumor homing potential. We therefore examined the potential of GTGKT peptide as anti-cancer peptide in association with its potential effect 
on the expression of cyclinD1 and the binding of CAGE to GSK3 $\beta$. FITC-labeled GTGKT peptide showed expression in Malme $3 \mathrm{M}^{\mathrm{R}}$ cells (Figure 2A). GTGKT and biotinGTGKT peptide decreased the expression of cyclinD1 and pGSK $3 \beta^{\text {Ser9 }}$, but not the expression of CAGE (Figure $2 B$ ). GTGKT and biotin-GTGKT peptide inhibited the binding of CAGE to GSK3 $\beta$ in SNU387 ${ }^{\mathrm{R}}$ and Malme $3 \mathrm{M}^{\mathrm{R}}$ cells (Figure 2B). GTGKT or biotin-labeled GTGKT peptide did not change the expression of CAGE in Malme $3 \mathrm{M}^{\mathrm{R}-}$ Taxol cell line, an anti-cancer drug-resistant cancer cell line made resistant to taxol (Figure 2C). GTGKT and biotin-labeled GTGKT peptide decreased the expression of cyclinD1 and pGSK3 $\beta^{\text {Ser9 }}$, and inhibited the binding of CAGE to GSK3 $\beta$ in Malme3 $\mathrm{M}^{\mathrm{R} \text {-Taxol }}$ cell line (Figure $2 \mathrm{C}$ ). Biotin-labeled GTGKT peptide showed binding to CAGE, but not to GSK3 $\beta$ in Malme $3 \mathrm{M}^{\mathrm{R} \text {-Taxol }}$ cells (Figure $2 \mathrm{C}$ ) and Malme $3 \mathrm{M}^{\mathrm{R}}$ cells (data shown). GTGKT, but not SQAWP

A
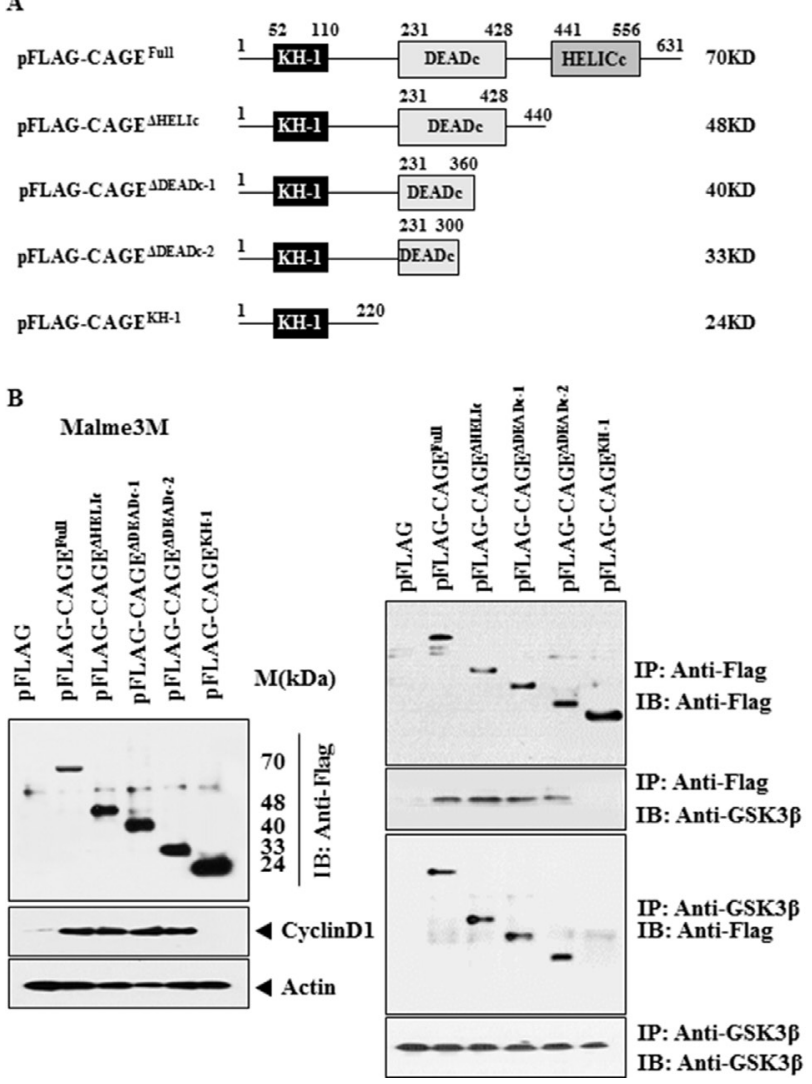

or RNGPG peptide, decreased the expression of cyclinD1 in Malme $3 \mathrm{M}^{\mathrm{R}}$ cells (Figure 2D). GTGKT, but not SQAWP or RNGPG peptide within DEAD box domain of CAGE (amino acids 231-300), inhibited the binding of CAGE to GSK $3 \beta$ in Malme $3 \mathrm{M}^{\mathrm{R}}$ cells (Figure 2D). We therefore focused on GTGKT peptide throughout this study. These results suggest that GTGKT peptide displays anti-cancer activity by inhibiting the binding of CAGE to GSK3 $\beta$ in anti-cancer drug-resistant cancer cells.

\section{GTGKT peptide binding to CAGE is necessary for conferring sensitivity to anti-cancer drugs}

Because GTGKT peptide inhibited the binding of CAGE to GSK3 $\beta$ (Figure $2 \mathrm{~B}$ and $2 \mathrm{C}$ ), we examined the importance of GTGKT peptide binding to CAGE or GSK3 $\beta$. For this, full-length CAGE or each CAGE deletion
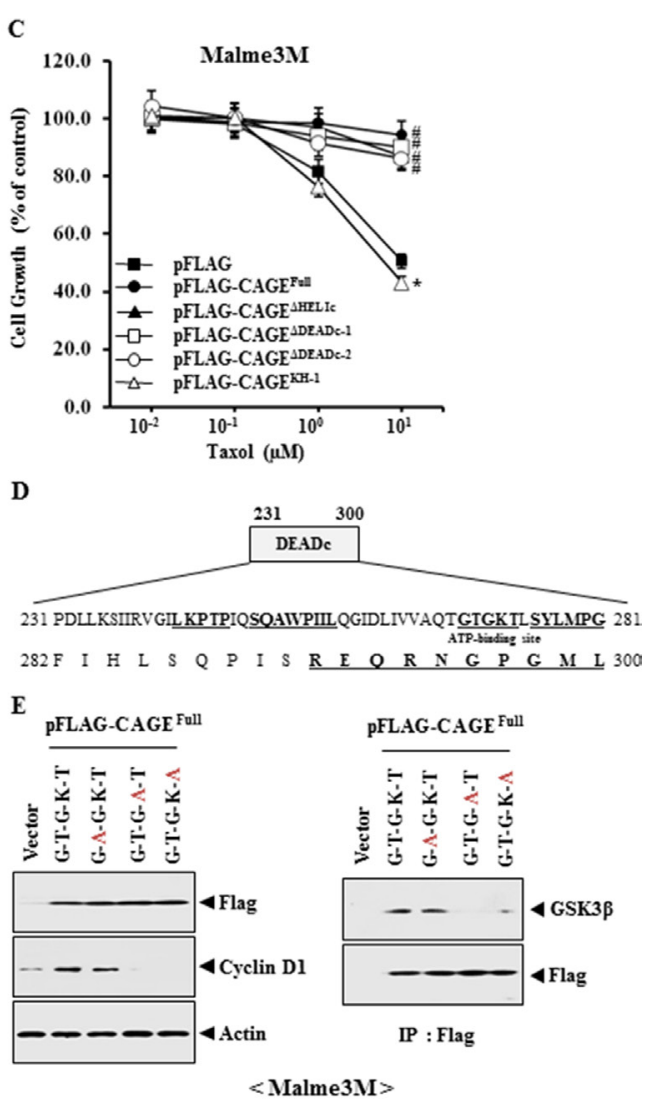

Figure 1: CAGE domain encompassing amino acids 231-300 is necessary for binding of CAGE to GSK3ß and for increasing the expression of cyclinD1. (A) Shows a series of CAGE deletion constructs. FL denotes full-length. (B) Malme3M cells were transiently transfected with each CAGE construct $(1 \mu \mathrm{g})$. At $48 \mathrm{~h}$ after transfection, cell lysates were subjected to Western blot analysis (left panel). Cell lysates were immunoprecipitated with the indicated antibody $(2 \mu \mathrm{g} / \mathrm{ml})$, followed by Western blot analysis (right panel). A representative of at least two reproducible results is shown. (C) Malme3M cells were transiently transfected with each CAGE construct $(1 \mu \mathrm{g})$. At $24 \mathrm{~h}$ after transfection, cells were treated with various concentrations of taxol for $24 \mathrm{~h}$, followed by MTT assays. The mean \pm S.E. of three independent experiments is shown. ${ }^{*} p<0.05 ;{ }^{*} p<0.05$. *; comparison was made between Malme $3 \mathrm{M}$ cells transfected with $\mathrm{CAGE}^{\mathrm{KH}-1}$ deletion construct and the same cells transfected with CAGE ${ }^{\text {Full. }}$ \#; comparison was made between Malme3M cells transfected with the indicated construct and the same cells transfected with pFLAG. (D) Shows putative binding sites within the DEAD box domain of CAGE. The bold underlined peptides denote peptides with potential tumor homing activity. (E) Malme3M cells were transiently transfected with the indicated construct $(1 \mu \mathrm{g})$. At $48 \mathrm{~h}$ after transfection, cell lysates were subjected to immunoprecipitation and Western blot analysis. A representative of at least two reproducible results is shown. 
construct was transfected into Malme3M Cells. Cells were then treated with GTGKT peptide. GTGKT peptide showed binding to full-length CAGE (Supplementary Figure 5A). However, GTGKT peptide did not show binding to any other CAGE deletion constructs (Supplementary Figure 5A). This suggests that the binding domain of GTGKT resides in helicase domain of CAGE (amino acids 441-631). GTGKT peptide did not show binding to GSK3 $\beta$ (Supplementary Figure 5A). We next examined whether GTGKT binding to CAGE would be necessary for enhancing the response to anti-cancer drugs. GTGKT peptide conferred sensitivity to taxol in Malme3M cells transfected with full-length CAGE (Supplementary Figure 5B). CAGE deletion constructs, such as pFLAG-CAGE ${ }^{\triangle \mathrm{HELIc}}$, pFLAG-CAGE ${ }^{\triangle \mathrm{DEADc}-1}$ and $\mathrm{pFLAG-}$ $\mathrm{CAGE}^{\triangle \mathrm{DEADc}-2}$, conferred resistance to taxol in Malme3M cells (Supplementary Figure 5B). GTGKT peptide did not enhance caspase- 3 activity in Malme $3 \mathrm{M}$ cells transfected with pFLAG-CAGE ${ }^{\triangle \mathrm{HELIc}}$, pFLAG-CAGE ${ }^{\triangle \mathrm{DEADc}-1}$ or
pFLAG-CAGE ${ }^{\triangle \mathrm{DEADc}-2}$ construct in response to celastrol or taxol (Supplementary Figure 5C). GTGKT peptide did not induce cleavage of PARP in Malme3M cells transfected with $p F L A G-C A G E^{\triangle H E L I c}$, pFLAG-CAGE ${ }^{\triangle D E A D c-1}$ or pFLAG$\mathrm{CAGE}^{\triangle \mathrm{DEADc}-2}$ construct in response to taxol (Supplementary Figure 5D). Because GTGKT peptide showed binding to CAGE (Supplementary Figure 5A), we examined whether GTGKT peptide showed a co-localization with CAGE. CAGE and FITC-GTGKT peptide showed localization in the nucleus and cytoplasm in Malme $3 \mathrm{M}^{\mathrm{R}}$ cells (Supplementary Figure 6). CAGE showed mostly cytoplasmic localization in Malme $3 \mathrm{M}^{\mathrm{R}}$ cells treated with FITC-GTGKT peptide (Supplementary Figure 6). CAGE showed co-localization with GTGKT peptide in the cytoplasm in Malme $3 \mathrm{M}^{\mathrm{R}}$ cells (Supplementary Figure 6). This implies that GTGKT peptide prevents nuclear localization of CAGE. These results suggest that GTGKT peptide binding to CAGE is necessary for conferring sensitivity to anti-cancer drugs.
A

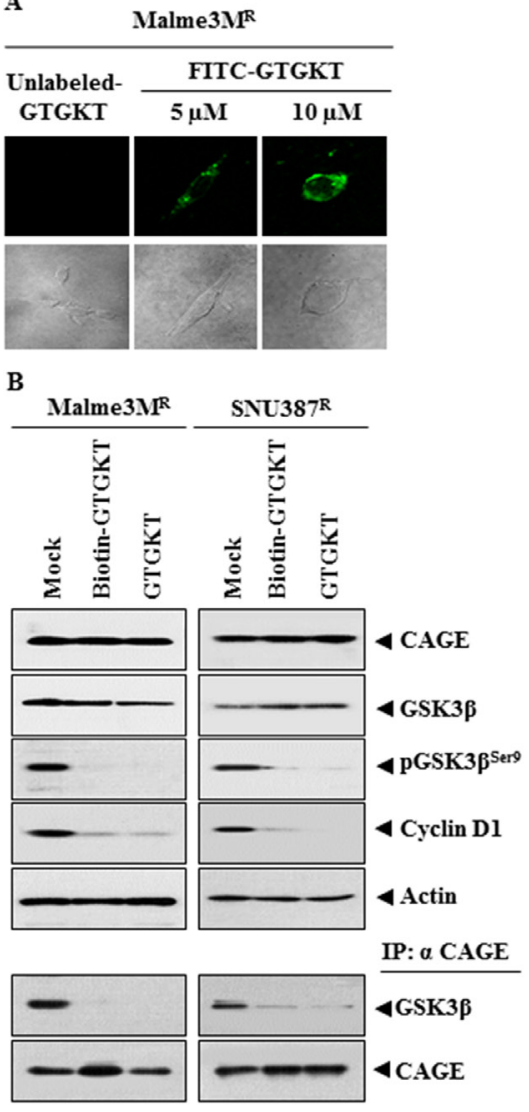

C

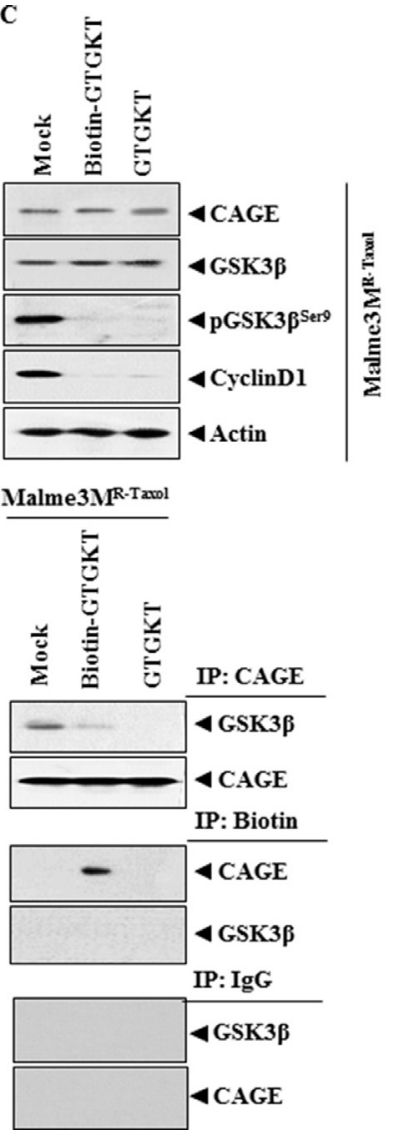

D

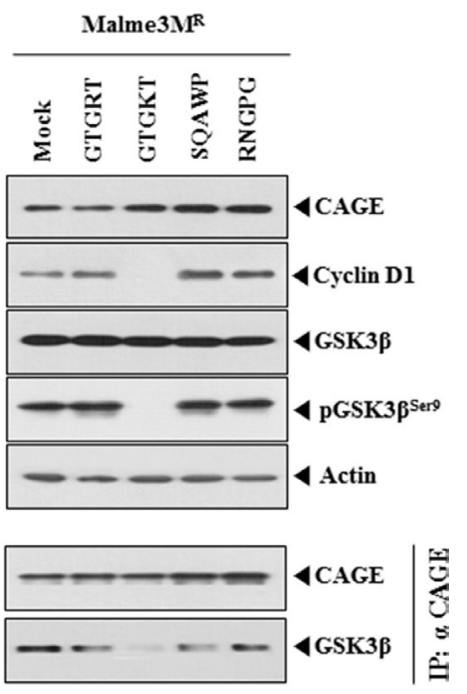

Figure 2: GTGKT peptide decreases the expression of cyclinD1, pGSK3 $\beta^{\mathrm{Ser} 9}$ and inhibits the binding of CAGE to GSK3ß. (A) Malme $3 \mathrm{M}^{\mathrm{R}}$ cells were treated with FITC-labeled GTGKT peptide $(5,10 \mu \mathrm{M})$ or unlabeled GTGKT peptide $(10 \mu \mathrm{M})$. At $48 \mathrm{~h}$ after treatment, the expression of GTGKT peptide was determined. (B) Malme3 $\mathrm{M}^{\mathrm{R}}$ or SNU387 ${ }^{\mathrm{R}}$ cells were treated with the indicated peptide $(10 \mu \mathrm{M})$. At $48 \mathrm{~h}$ after treatment, cell lysates were subjected to Western blot analysis Cell lysates prepared were subjected to immunoprecipitation, followed by Western blot analysis (lower panel). A representative of at least two reproducible results is shown. (C) Malme $3 \mathrm{M}^{\mathrm{R} \text {-taxol }}$ cells were treated with the indicated peptide $(10 \mu \mathrm{M})$. At $48 \mathrm{~h}$ after treatment, cell lysates prepared were subjected to Western blot analysis. Cell lysates prepared were subjected to immunoprecipitation, followed by Western blot analysis (lower panel). A representative of at least two reproducible results is shown. (D) The indicated cancer cells were treated with the indicated peptide (10 $\mu \mathrm{M})$. At $48 \mathrm{~h}$ after treatment, cell lysates prepared were subjected to immunoprecipitation and Western blot analysis. A representative of at least two reproducible results is shown. 


\section{GTGKT peptide changes localization of CAGE to inhibit the binding of CAGE to the promoter sequences of cyclinD1}

Because GTGKT peptide inhibited the binding of CAGE to GSK3 $\beta$ (Figure 2A) and also showed binding to CAGE (Figure 2B), we examined whether GTGKT peptide would inhibit the function of CAGE. CAGE showed the binding to the promoter sequences of cyclinD1 (Supplementary Figure 3B). We hypothesized that GTGKT peptide would inhibit the binding of CAGE to the promoter sequences of cyclinD1. We hypothesized that SP1, through binding to CAGE, might increase the expression of cyclinD1. In Malme $3 \mathrm{M}^{\mathrm{R}}$ cells, SP1 showed nuclear localization while CAGE was present in both nucleus and cytoplasm (Figure 3A). CAGE showed a co-localization with SP1 in Malme $3 \mathrm{M}^{\mathrm{R}}$ cells (Figure $3 \mathrm{~A}$ ). Immunofluorescence staining revealed that GTGKT peptide did not change the expression of CAGE or SP1 in (Figure 3A). However, GTGKT peptide changed the localization of CAGE into cytoplasmic, which inhibited co-localization of CAGE with SP1 (Figure 3A). Immunofluorescence staining revealed that Malme $3 \mathrm{M}^{\mathrm{R}}$ cells that stably express anti-sense CAGE (Malme3M ${ }^{\text {R-As-CAGE}) ~ d i d ~ n o t ~ e x p r e s s ~ S P 1 ~(F i g u r e ~ 3 A) . ~ T h e ~}$ expression level of SP1 was higher in Malme $3 \mathrm{M}^{\mathrm{R}}$ cells (Figure 3B). GTGKT peptide did not change the expression of CAGE in Malme $3 \mathrm{M}^{\mathrm{R}}$ cells (Figure 3B). The fact that GTGKT peptide changes the localization of CAGE and decreases the expression of cyclinD1 without changing the expression level of SP1 implies that GTGKT peptide exerts a transcriptional regulation on the expression of cyclinD1. The down-regulation of SP1 decreased the expression of CAGE and cyclin D1 (Figure 3C). The down-regulation of SP1 enhanced the sensitivity to anti-cancer drugs (Supplementary Figure 7A), the cleavage of FAK (Supplementary Figure 7B) and the caspase-3 activity (Supplementary Figure 7C) in response to anti-cancer drugs in Malme $3 \mathrm{M}^{\mathrm{R}}$ cells. The down-regulation of SP1 decreased the invasion and migration potential of Malme $3 \mathrm{M}^{\mathrm{R}}$ cells (Supplementary Figure 7D). Just like CAGE, SP1 showed the binding to the promoter sequences of cyclinD1 in Malme $3 \mathrm{M}^{\mathrm{R}}$ cells (Figure 3D), suggesting the direct expression regulation of cyclinD1 by SP1. GTGKT peptide, but not GTGK peptide, prevented $\mathrm{CAGE}$ and $\mathrm{HDAC} 2$ from binding to the promoter sequences of cyclinD1 in Malme3M $\mathrm{M}^{\mathrm{R}}$ cells (Figure 3E). CAGE showed the binding to SP1 (data not shown). GTGKT peptide, but not GTGK peptide, inhibited the binding of CAGE to SP1 (data not shown). These results suggest that GTGKT peptide may cause structural changes to CAGE, which in turn inhibits the binding of CAGE to the promoter sequences of cyclinD1.

\section{GTGKT peptide decreases the tumorigenic potential of anti-cancer drug-resistant cancer cells}

We first examined the effect of CAGE on the tumorigenic potential and the in vivo response to taxol. Malme3M $\mathrm{M}^{\mathrm{R}-\mathrm{As}-\mathrm{CAGE}}$ cells that stably express anti- sense CAGE showed lower tumorigenic potential than Malme $3 \mathrm{M}^{\mathrm{R}}$ cells and showed higher sensitivity to taxol than Malme3M ${ }^{R}$ cells (Supplementary Figure 8A). The xenograft of Malme $3 \mathrm{M}^{\text {R-As-CAGE }}$ cells showed lower expression level of CAGE, cyclinD1 and pGSK3 $\beta^{\text {Ser9 }}$ while showing higher expression level of phosphocyclinD1 $1^{\text {Thr286 }}$ than the xenograft of Malme $3 \mathrm{M}^{\mathrm{R} \text {-vector }}$ cells (Supplementary Figure 8B). The in vivo downregulation of CAGE by CAGE siRNA also decreased the tumorigenic potential of Malme $3 \mathrm{M}^{\mathrm{R}}$ cells (data not shown). We next examined the effect of GTGKT peptide on the tumorigenic potential of anti-cancer drug-resistant cancer cells. GTGKT peptide decreased the tumorigenic potential of SNU387 $7^{\mathrm{R}}$ and Malme $3 \mathrm{M}^{\mathrm{R}}$ cells (Figure 4A). Western blot of tumor tissue lysates show that GTGKT peptide decreased the expression of cyclinD1, pGSK3 $\beta^{\text {Ser9 }}$ and MDR1 while increasing the expression of phosphocyclinD $1^{\text {Thr286 }}$ (Figure 4B). Immunoprecipitation of tumor lysates showed that GTGKT peptide inhibited the binding of CAGE to GSK3 $\beta$ (Figure 4B). Unlike GTGKT peptide, GTGK peptide did not decrease the tumorigenic potential of Malme $3 \mathrm{M}^{\mathrm{R}}$ cells (Figure 4C), the expression of cyclinD1, pGSK $3 \beta^{\text {Ser9 }}$ or the binding of CAGE to GSK $3 \beta$ (Figure 4D). These results suggest that GTGKT peptide decreases the tumorigenic potential of cancer cells by decreasing the expression of cyclinD1, pGSK $3 \beta^{\text {Ser9 }}$ and inhibiting the binding of CAGE to GSK3 $\beta$.

\section{GTGKT peptide decreases the metastatic potential of anti-cancer drug-resistant cancer cells}

GTGKT peptide, but not GTGRT peptide, decreased the metastatic potential of Malme $3 \mathrm{M}^{\mathrm{R}}$ cells (Figure 5A). GTGKT peptide decreased the metastatic potential of Malme $3 \mathrm{M}^{\mathrm{R}}$ cells in a manner associated with its effect on the binding of CAGE to GSK3 $\beta$ (Figure 5B). Western blot analysis of tumor lysates showed that GTGKT peptide, but not GTGRT peptide, decreased the expression of cyclinD1, pGSK3 $\beta^{\text {Serg }}$ and MDR1 (Figure 5B). These results suggest that GTGKT peptide decreases the metastatic potential of Malme $3 \mathrm{M}^{\mathrm{R}}$ cells by decreasing the expression of cyclinD1 and inhibiting the binding of CAGE to GSK3 $\beta$.

\section{Lys $^{272}$ residue of ${ }^{269}$ GTGKT $^{273}$ peptide is necessary for conferring anti-cancer activity}

We wanted to determine residues of GTGKT peptide necessary for conferring sensitivity to anti-cancer drugs. GTGK peptide did not change the expression of cyclinD1, phospho-cyclinD1 ${ }^{\text {Thr286 }}$ or the binding of CAGE to GSK3 $\beta$ (Figure 6A). This suggests that the length of peptide corresponding to the DEAD box helicase domain of CAGE is necessary for conferring anti-cancer activity. GTGRT peptide did not change the expression level of cyclinD1, phospho-cyclinD1 $1^{\text {Thr286 }}$ or the binding of CAGE to GSK3 $\beta$ (Figure 6A). GTGKT and GTGKA peptides decreased the expression of cyclinD1 while increasing 
the expression of phospho-cyclinD $1^{\text {Thr286 }}$ and inhibiting the binding of CAGE to GSK3 $\beta$ (Figure 6A). GTGKA peptide, but not GTGRT or GTGAT peptide, induced cleavage of PARP and FAK in response to celastrol and taxol in Malme3 $\mathrm{M}^{\mathrm{R}}$ cells (Figure 6B). GTGKT peptide, but not GTGRT or GTGAT peptide, decreased the expression of cyclinD1, and pGSK $3 \beta^{\text {Ser9 }}$ while increasing the expression of phospho-cyclinD1 $1^{\text {Thr286 }}$ and inhibited the binding of CAGE to GSK3 $\beta$ (Figure 6C). GAGKT peptide did not change the expression level of cyclinD1 in Malme $3 \mathrm{M}^{\mathrm{R}}$ cells (data not shown). These results suggest that Lys $^{272}$ residue of GTGKT peptide is necessary for conferring anti-cancer activity.

\section{TGTGKT, QTGTGKT and AQTGTGKT peptides enhance apoptotic effects of anti-cancer drugs}

We examined the anti-cancer activity of other peptides corresponding to the DEAD box helicase domain of CAGE.
${ }^{268}$ TGTGKT $^{273},{ }^{267}$ QTGTGKT $^{273}$ and ${ }^{266}$ AQTGTGKT $^{273}$ peptides decreased the expression of cyclin D1 and pGSK $3 \beta^{\text {Ser9 }}$ and inhibited the binding of CAGE to GSK $3 \beta$ (Figure 7A). ${ }^{266} \mathrm{AQTGTGKT}{ }^{273}$ peptide prevented the binding of CAGE to the promoter sequences of cyclinD1 based on ChIP assays (data not shown). D-GTGKT and D-AQTGTGKT peptides inhibited the binding of CAGE to GSK3 $\beta$ (Figure 7B). GTGKT, TGTGKT, QTGTGKT and AQTGTGKT peptides, but not GTGRT peptide, increased caspase-3 activity in response to celastrol and taxol in Malme $3 \mathrm{M}^{\mathrm{R}}$ cells (Figure 7C). TGTGKT, QTGTGKT and AQTGTGKT peptides induced the cleavage of PARP and FAK in response to celastrol and taxol (Figure 7D). AQTGTGKT and FITC-labeled AQTGTGKT peptides decreased the expression of cyclinD1 and pGSK3 $\beta^{\mathrm{Ser} 9}$ in Malme $3 \mathrm{M}^{\mathrm{R}}$ cells (Figure 7E). FITC-labeled AQTGTGKT peptide showed expression in Malme $3 \mathrm{M}^{\mathrm{R}}$ cells (Figure $7 \mathrm{~F}$ ). These results indicate that peptides within DEAD box domain of CAGE enhance apoptotic effects of anti-cancer drugs by
A

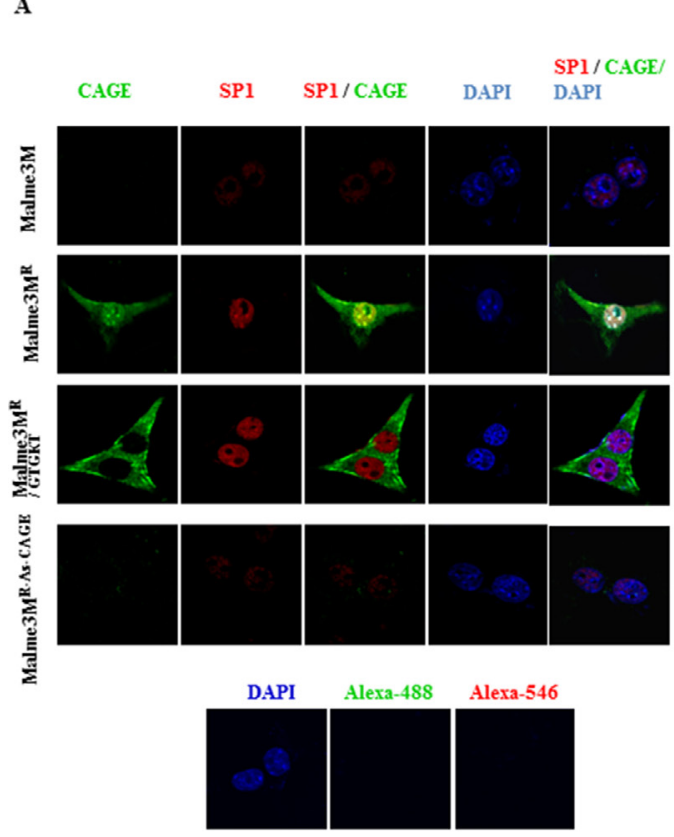

B

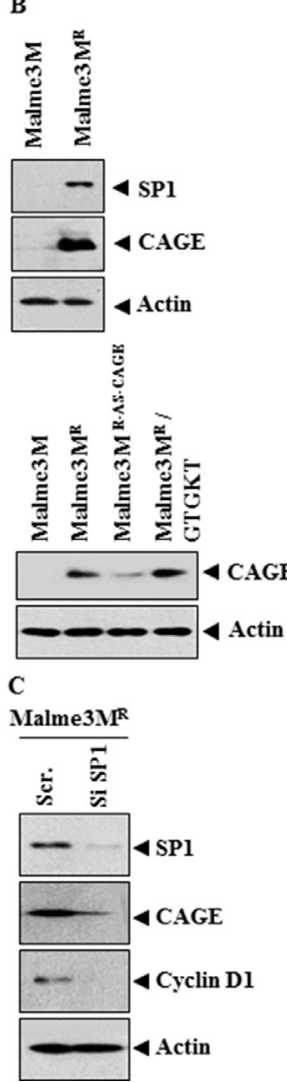

D

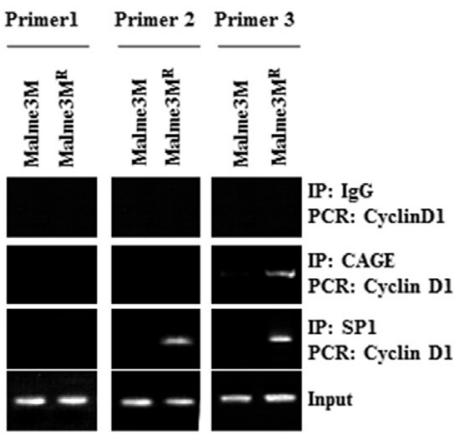

E
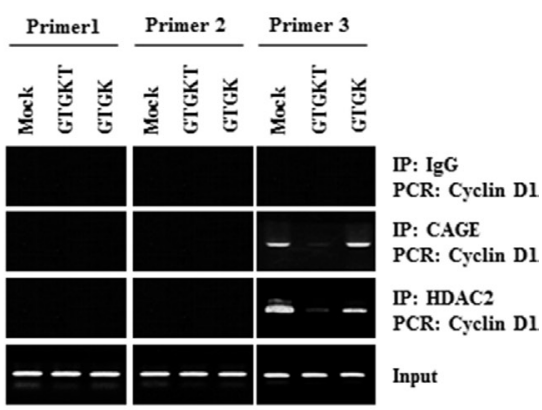

Figure 3: GTGKT peptide changes localization of CAGE to inhibit the binding of CAGE to the promoter sequences of cyclinD1. (A) Immunofluorescence staining employing the indicated antibody was performed. Malme $3 \mathrm{M}^{\mathrm{R}-\mathrm{AS}-\mathrm{CAGE}}$ cells denote Malme $3 \mathrm{M}^{\mathrm{R}}$ cells that stably express anti-sense CAGE. Malme $3 \mathrm{M}^{\mathrm{R}}$ cells were treated with the indicated peptide $(10 \mu \mathrm{M})$. At $48 \mathrm{~h}$ after treatment, cells were then subjected to immunofluorescence staining. (B) Cell lysates from the indicated cancer cells were subjected to Western blot analysis (upper panel). Malme $3 \mathrm{M}^{\mathrm{R}}$ cells were treated with the indicated peptide $(10 \mu \mathrm{M})$. At $48 \mathrm{~h}$ after treatment, cell lysates were subjected to Western blot analysis (lower panel). Cell lysates isolated from Malme3M, Malme $3 \mathrm{M}^{\mathrm{R}}$ or Malme $3 \mathrm{M}^{\mathrm{R}-\mathrm{AS} \text {-CAGE }}$ cells were subjected to Western blot analysis (lower panel). (C) Malme $3 \mathrm{M}^{\mathrm{R}}$ cells were transiently transfected with the indicated siRNA (each at $10 \mathrm{nM}$ ). At $48 \mathrm{~h}$ after transfection, cell lysates were subjected to Western blot analysis. (D) Cell lysates isolated from the indicated cancer cells were subjected to ChIP assays. (E) Malme $3 \mathrm{M}^{\mathrm{R}}$ cells were treated with the indicated peptide $(10 \mu \mathrm{M})$. At $48 \mathrm{~h}$ after treatment, cell lysates prepared were subjected to ChIP assays. 
decreasing the expression of cyclinD1, pGSK $3 \beta^{\text {Serg }}$ and the binding of CAGE to GSK3 $\beta$.

\section{Peptides corresponding to the DEAD box helicase domain of CAGE decrease the migration, invasion and angiogenic potential of anti-cancer drug-resistant cancer cells}

Various peptides corresponding to the DEAD box helicase domain of CAGE, but not GTGRT peptide, decreased the migration potential (Figure 8A) and the invasion potential of Malme $3 \mathrm{M}^{\mathrm{R}}$ cells (Figure $8 \mathrm{~B}$ ). GSK3 $\beta$ decreases the angiogenesis by decreasing the expression of HIF-1 $\alpha$ via phosphorylation and recruitment of ubiquitin ligase [25]. Recombinant CAGE protein displays angiogenic potential [8]. We examined the effect of peptides corresponding to the DEAD box helicase domain of CAGE on the angiogenic potential of anti-cancer drugresistant cancer cells. The conditioned medium obtained from Malme $3 \mathrm{M}^{\mathrm{R}}$ cells treated with GTGKT, D-GTGKT or AQTGTGKT, but not treated with GTGK, inhibited the angiogenic potential of Malme $3 \mathrm{M}^{\mathrm{R}}$ cells based on intravital microscopy (Figure 8C). The conditioned medium of Malme $3 \mathrm{M}^{\mathrm{R}}$ cells treated with GTGKT, D-GTGKT or AQTGTGKT, when added to HUVECs, inhibited endothelial cell tube formation (Figure 8C). These results suggest that peptides corresponding to the DEAD box helicase domain of CAGE decrease the migration, invasion and angiogenic potential of cancer cells by binding to CAGE.
A

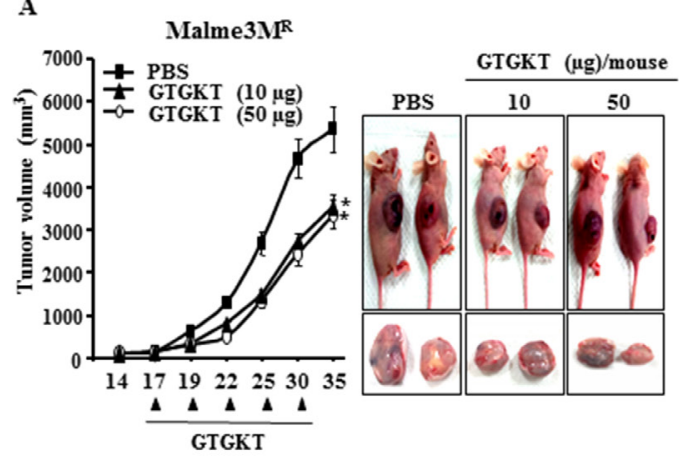

B

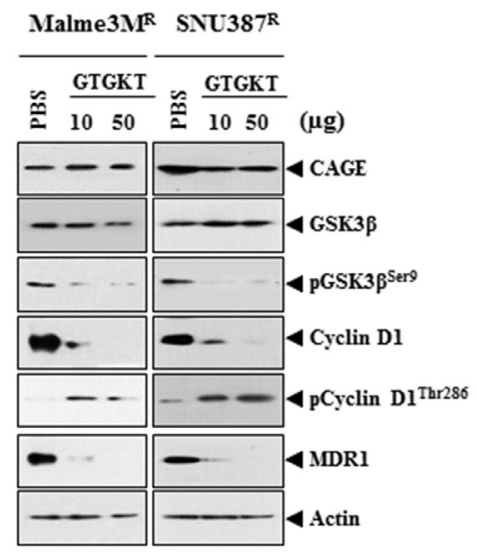

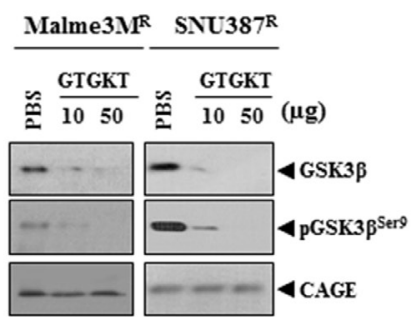

IP: CAGE

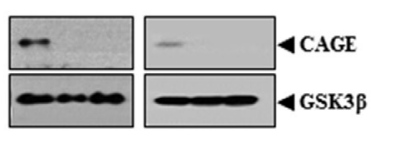

IP: GSK3 $\beta$
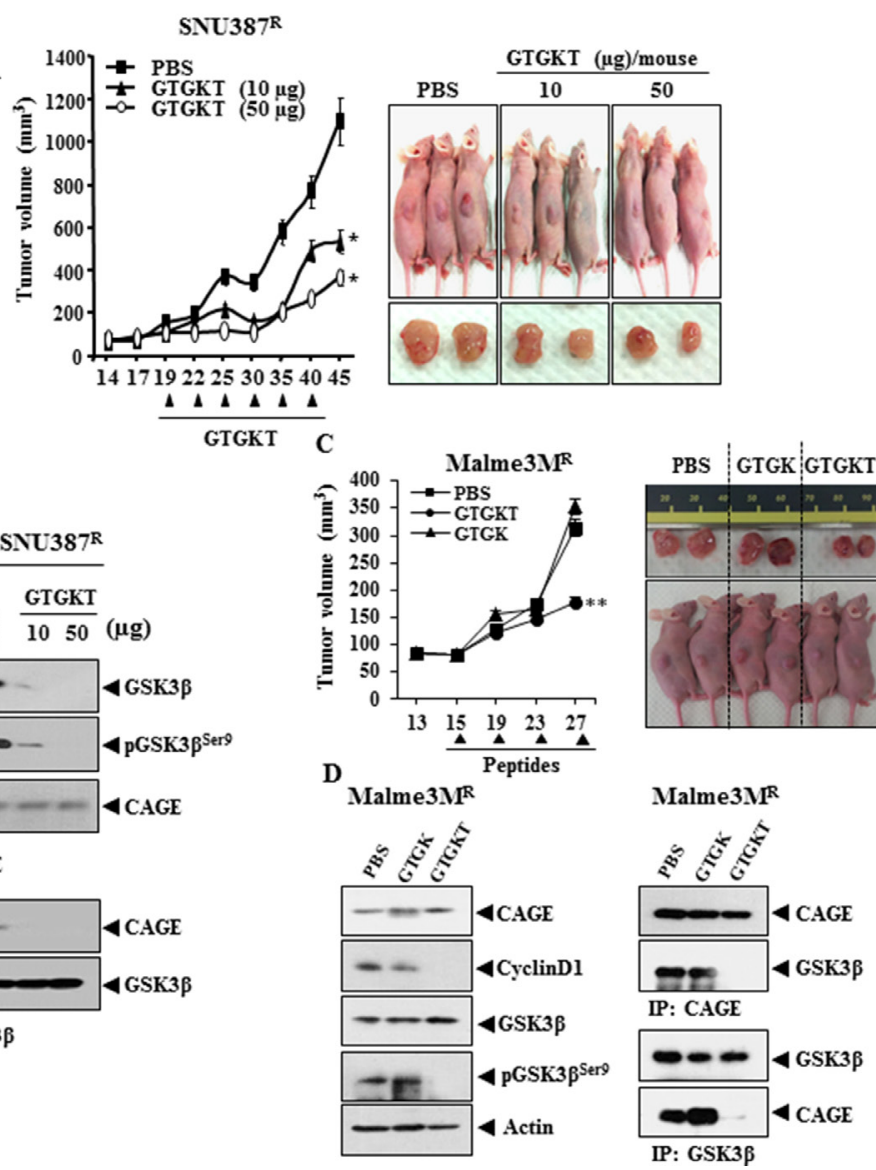

Figure 4: GTGKT peptide decreases the tumorigenic potential of anti-cancer drug-resistant cancer cells. $(A) \mathrm{Malme} 3 \mathrm{M}^{\mathrm{R}}$ $\left(1 \times 10^{6}\right)$ or SNU387R $\left(1 \times 10^{6}\right)$ cells were injected into the dorsal flanks of athymic nude mice. Following the establishment of sizeable tumor, GTGKT peptide (10 $\mathrm{g} / \mathrm{mouse}$ or $50 \mu \mathrm{g} / \mathrm{mouse})$ was injected into the tail vein. Each experimental group consisted of five mice. Each value represents an average obtained from the five athymic nude mice of each group. Data are expressed as a mean \pm S.D. Each figure shows a representative image of the mice in each group at the time of sacrifice. Comparison was made between group of mice injected with GTGKT peptide (10 $\mu \mathrm{g} / \mathrm{mouse}$ or $50 \mu \mathrm{g}$ /mouse) and group of mice injected with PBS. ${ }^{*} p<0.05$. (B) Tumor lysates were subjected to Western blot analysis (left panel). Tumor lysates were also immunoprecipitated with the indicated antibody $(2 \mu \mathrm{g} / \mathrm{ml})$, followed by Western blot analysis (right panel). $(\mathbf{C})$ Malme $3 \mathrm{M}^{\mathrm{R}}\left(1 \times 10^{6}\right)$ cells were injected into the dorsal flanks of athymic nude mice. Following the establishment of sizeable tumor, GTGKT or GTGK peptide (each at $50 \mu \mathrm{g} / \mathrm{mouse}$ ) was injected into the tail vein. Each experimental group consisted of five mice. Comparison was made between group of mice injected with GTGKT peptide (50 $\mu \mathrm{g} / \mathrm{mouse})$ and group of mice injected with GTGK peptide. ${ }^{*} p<0.005$. (D) Tumor lysates were subjected to Western blot analysis (left panel). Tumor lysates were also immunoprecipitated with the indicated antibody $(2 \mu \mathrm{g} / \mathrm{ml})$, followed by Western blot analysis (right panel). 


\section{AQTGTGKT peptide decreases the tumorigenic and metastatic potential of anti-cancer drug- resistant cancer cells}

Because AQTGTGKT peptide exerted an anti-cancer activity in vitro, we examined the in vivo anti-cancer activity of AQTGTGKT peptide. AQTGTGKT peptide decreased the tumorigenic potential of Malme $3 \mathrm{M}^{\mathrm{R}}$ cells (Figure 9A). AQTGTGKT peptide enhanced the in vivo sensitivity of Malme $3 \mathrm{M}^{\mathrm{R}}$ cells to anti-cancer drugs (Figure 9A). AQTGTGKT peptide decreased the expression of cyclinD1, pGSK3 $\beta^{\text {Serg } 9}$ and MDR1 (Figure 9B). AQTGTGKT peptide inhibited the binding of CAGE to GSK3 $\beta$ (Figure 9B). AQTGTGKT peptide decreased the metastatic potential of Malme $3 \mathrm{M}^{\mathrm{R}}$ cells in a manner associated with the inhibition of the binding of CAGE to GSK3 $\beta$ (Figure 9C). Western blot analysis of tumor lysates showed that AQTGTGKT peptide decreased the expression of cyclinD1, pGSK3 $\beta^{\text {Ser9 }}$ and MDR1 (Figure 9C). Therefore the in vivo anti-cancer activity of AQTGTGKT peptide results from its effect on the expression of and cyclinD1 and the binding of CAGE to GSK3 $\beta$.

\section{Peptides corresponding to the DEAD box helicase domain of CAGE enhance sensitivity to anti-cancer drugs in Malme3M cells transfected with miR-200b inhibitor}

miR-200b confers sensitivity to anti-cancer drugs by decreasing the expression of CAGE [8]. Peptides corresponding to the DEAD box helicase domain of CAGE, but not GTGRT peptide, prevented miR-200b inhibitor from conferring resistance to celastrol and taxol (Figure 10A). miR-200b inhibitor increased the expression of CAGE, cyclinD1 and induced the binding of CAGE to GSK3 $\beta$ (Figure 10A). Malme $3 \mathrm{M}^{\mathrm{R}-\mathrm{miR}-200 \mathrm{~b}}$ cells that stably express miR-200b did not show the binding of CAGE to GSK3 $\beta$ (Figure 10A). GTGKT, D-GTGKT, AQTGTGKT and D-AQTGTGKT peptides, but not GTGRT peptide, prevented miR-200b inhibitor from increasing the expression of cyclinD1 in Malme3M cells (Figure 10B). miR-200b inhibitor prevented cleavage of PARP and FAK in response to celastrol and taxol in Malme3M cells (Figure 10C). GTGKT and AQTGTGKT peptides, but not GTGRT peptide, enhanced the caspse-3 activity,

A

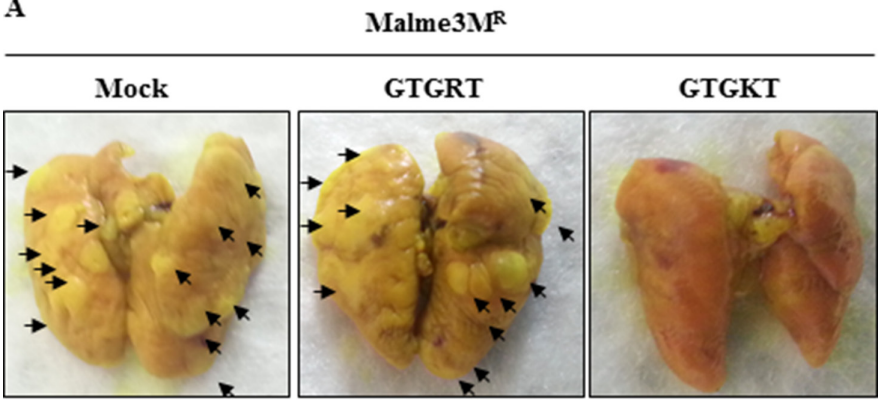

B
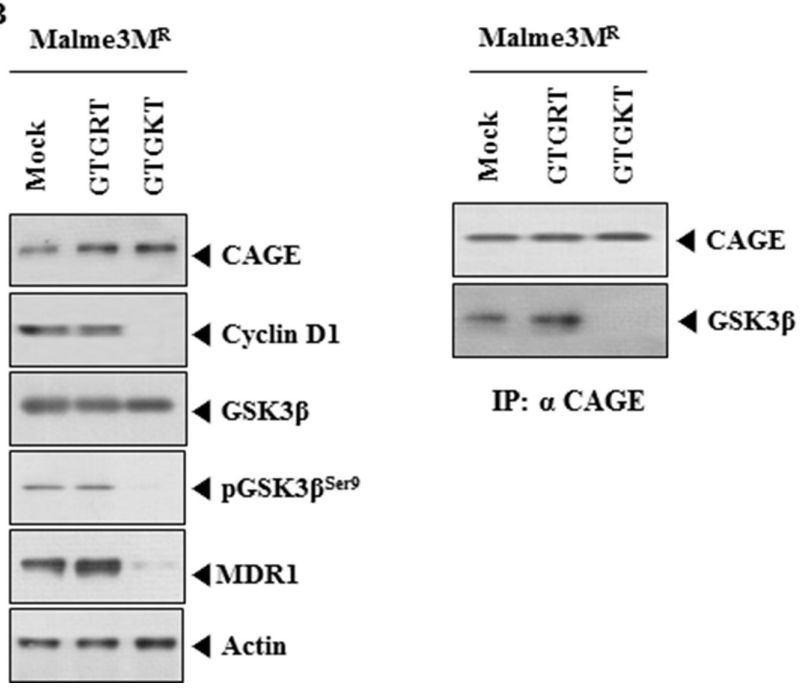

IP: $\alpha$ CAGE

Figure 5: GTGKT peptide decreases the metastatic potential of Malme3 $\mathrm{M}^{\mathrm{R}}$ cells. (A) Each experimental group consists of five athymic nude mice. Each figure shows a representative image of the mice in each experimental group. Malme $3 \mathrm{M}^{\mathrm{R}} \mathrm{Cells}\left(1 \times 10^{6}\right)$ were injected intravenously into the tail vein of 4-week-old athymic nude mice, and the extent of lung metastasis was evaluated. GTGRT peptide or GTGKT peptide (each at $50 \mu \mathrm{g} /$ mouse) was intravenously injected five times over a total of 4 weeks. (B) Lysates were subjected to Western blot analysis (left panel). Tumor lysates were also immunoprecipitated with the indicated antibody $(2 \mu \mathrm{g} / \mathrm{ml})$, followed by Western blot analysis (right panel). 
in response to celastrol and taxol, in Malme3M cells transfected with miR-200b inhibitor (Figure 10D). These results confirm that GTGKT and AQTGTGKT peptides confer sensitivity to anti-cancer drugs by inactivation of CAGE.

\section{GTGKT peptide shows ex vivo tumor homing potential}

Because GTGKT peptide decreased the tumorigenic potential (Figure 4A) and the metastatic potential (Figure $5 \mathrm{~A}$ ) of Malme $3 \mathrm{M}^{\mathrm{R}}$ cells, we examined whether GTGKT peptide would display tumor homing potential. BALB/C mice injected with unlabeled GTGKT peptide or FITC-GTGKT peptide showed little fluorescence in any organs examined (Figure 11A). To determine the distribution of the FITC-conjugated GTGKT peptide in tumor bearing animals and examine whether FITCconjugated GTGKT peptide localizes to tumor in vivo, tumor xenografts (Malme3 $\mathrm{M}^{\mathrm{R}}$ cells) were injected intravenously with FITC-conjugated GTGKT peptide. The peptide was then allowed to circulate in the blood stream for 6 and 12 hours before tumors and control organs were excised. Strong and specific fluorescence was detected in tumor xenografts (Malme $3 \mathrm{M}^{\mathrm{R}}$ cells) after $12 \mathrm{hrs}$ injection with FITC-conjugated GTGKT peptide, while little labeling was seen in control organs (Figure 11B). These results show ex vivo tumor homing potential of GTGKT peptide.

\section{DISCUSSION}

CyclinD1 promotes tumor growth and confers resistance to cisplatin in pancreatic cancer cell lines [26]. The expression level of cyclinD1 is higher in anticancer drug-resistant Malme $3 \mathrm{M}^{\mathrm{R}}$ and $\mathrm{SNU} 387^{\mathrm{R}}$ cells than in Malme3M and SUN387 cells, respectively (Supplementary Figure 1A). The expression level of phospho-cyclinD1 $1^{\text {Thr286 }}$ is lower in Malme $3 \mathrm{M}^{\mathrm{R}}$ and SNU387 ${ }^{\mathrm{R}}$ cells than in Malme3M and SUN387 cells, respectively (Supplementary Figure 1A). Based on the fact that the expression level of CAGE is higher in Malme $3 \mathrm{M}^{\mathrm{R}}$ and SNU387 ${ }^{\mathrm{R}}$ cells than in Malme3M and SUN387 cells, these results suggest the role of cyclinD1 in anti-cancer
A

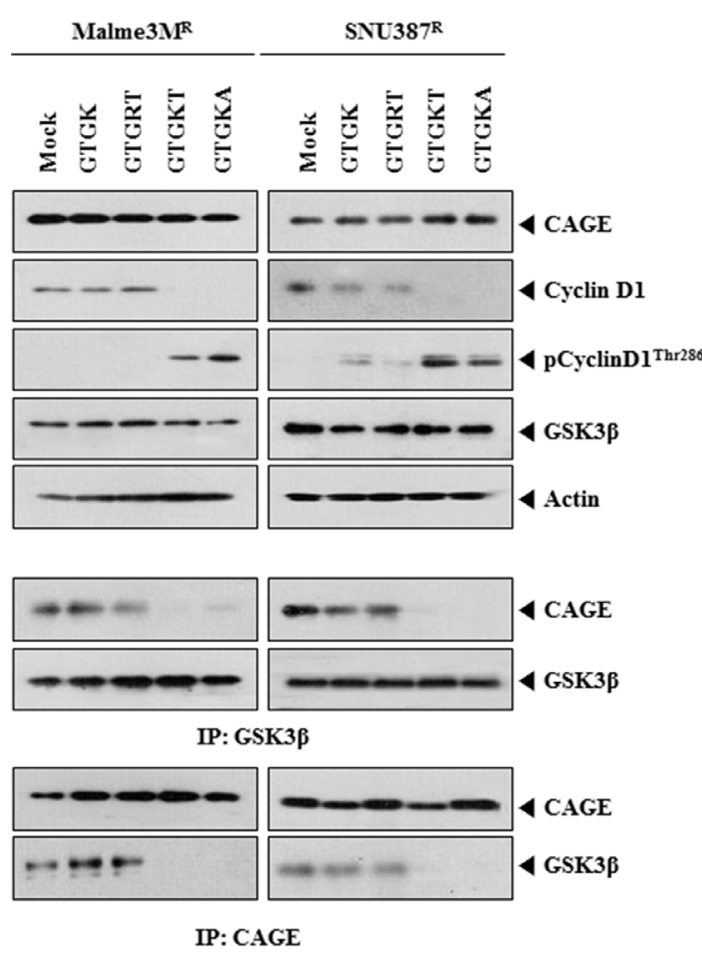

B

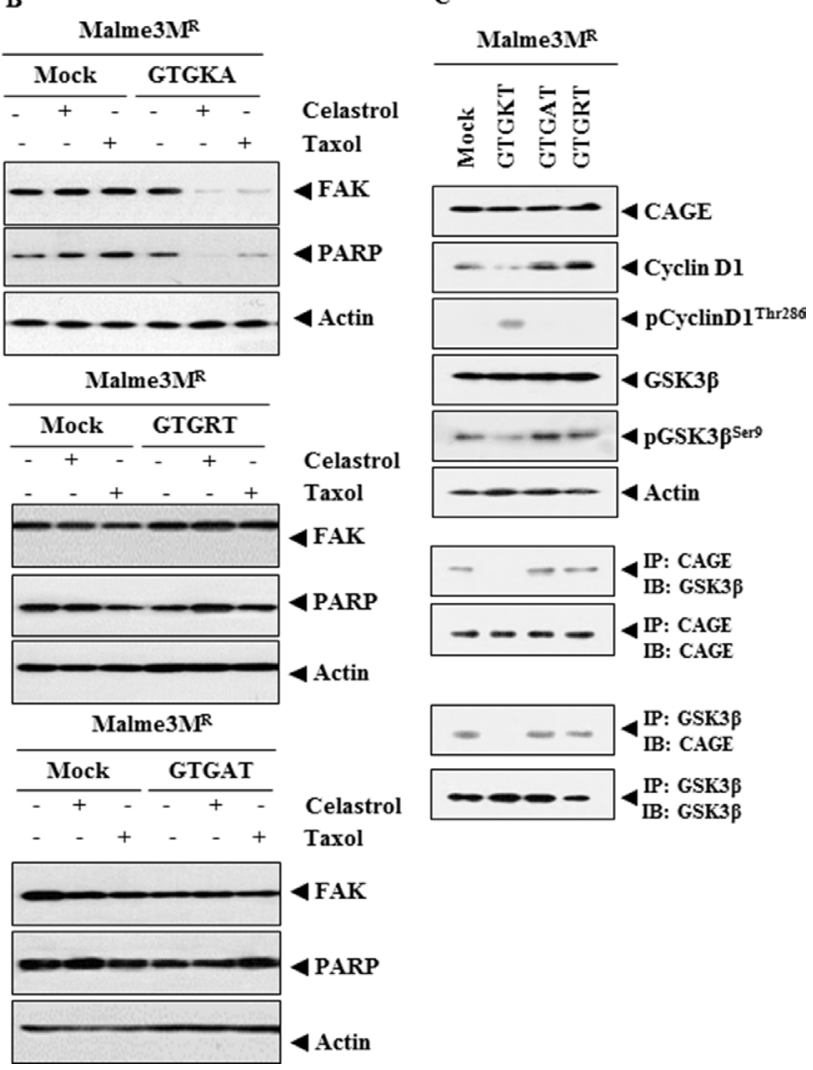

Figure 6: Lys $^{272}$ residue of ${ }^{269}$ GTGKT $^{273}$ peptide is necessary for anti-cancer activity. (A) Malme $3 \mathrm{M}^{\mathrm{R}}$ or $\mathrm{SNU} 387^{\mathrm{R}}$ cells were treated with the indicated peptide (each at $10 \mu \mathrm{M}$ ). At $48 \mathrm{~h}$ after transfection, cell lysates were subjected to Western blot analysis. Cell lysates were also immunoprecipitated with the indicated antibody $(2 \mu \mathrm{g} / \mathrm{ml})$, followed by Western blot analysis. (B) Malme $3 \mathrm{M}^{\mathrm{R}}$ cells were treated with the indicated peptide (each at $10 \mu \mathrm{M})$. At $24 \mathrm{~h}$ after treatment, cells were treated with celastrol $(1 \mu \mathrm{M})$ or taxol $(1 \mu \mathrm{M})$ for $24 \mathrm{~h}$. Cell lysates were then subjected to Western blot analysis. (C) Malme $3 \mathrm{M}^{\mathrm{R}}$ cells were treated with the indicated peptide (each at $\left.10 \mu \mathrm{M}\right)$. At $48 \mathrm{~h}$ after treatment, cell lysates were subjected to Western blot analysis. Cell lysates were also immunoprecipitated with the indicated antibody $(2 \mu \mathrm{g} / \mathrm{ml})$, followed by Western blot analysis. 
drug-resistance conferred by CAGE. It would be necessary to identify molecules functioning downstream of cyclinD1 for better understanding of anti-cancer drug-resistance conferred by CAGE. It would be also interesting to further identify miRNAs that decrease the expression of cyclinD1 and CAGE.

GSK $3 \beta$ accumulates in the nucleus and induces phosphorylation, nuclear export and subsequent degradation of cyclinD1 in the cytoplasm [27]. The phosphorylation of cyclinD1 at threonine 286 by glycogen synthase kinase 3 (GSK3) is required for the ubiquitination and nuclear export of cyclinD1 and its subsequent degradation in the proteasome $[27,28]$. We show the nuclear localization of phospho-cyclinD1 $1^{\text {Thr286 }}$ in Malme3M cells, but not in Malme3 $\mathrm{M}^{\mathrm{R}}$ cells (Supplementary Figure 1B). This suggests that the phosphorylation of cyclinD1 at Thr 286 in Malme3M cells may be responsible for the lack of expression of cyclinD1 in Malme3M cells. We reported that SIAH2, an ubiquitin ligase, binds to and decreases the expression of HDAC3 in Malme $3 \mathrm{M}^{\mathrm{R}}$ cells [29]. It would be interesting to examine whether SIAH2 decreases the expression of cyclinD1 in Malme3M cells.

miR-145, miR-133a and miR-133b decrease the expression of the transcription factor SP1, knockdown of which reduces the expression of cyclinD1 [30]. It is therefore reasonable that these miRNAs decrease the expression of CAGE. NGF induces the expression of cyclinD1 via SP1 and NF-kB [31]. CAGE shows colocalization with SP1 (Figure 3A). SP1 shows the binding to the promoter sequences of cyclin D1 (Figure 3D). GTGKT peptide does not change the expression of CAGE. However, GTGKT peptide inhibits nuclear localization of CAGE and prevents CAGE from binding to the promoter sequences of cyclinD1 (Figure 3E). The disruption of HDAC2 suppresses the expression of cyclinD1, CDK4 and CDK2 [32]. Promoter analysis of cyclinD1
A

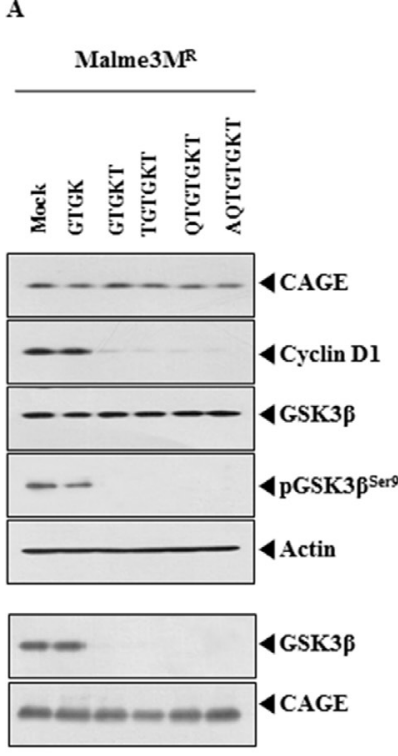

IP: CAGE

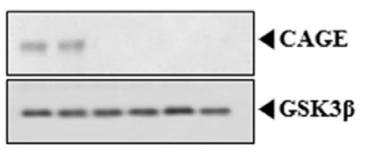

IP: GSK3 $\beta$
B

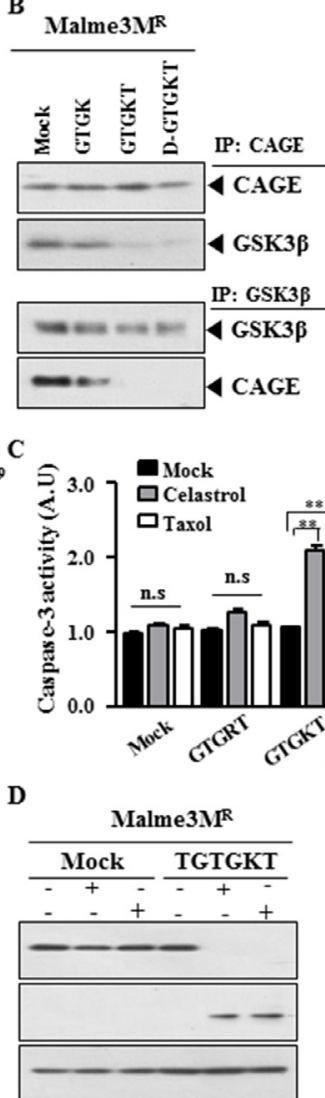

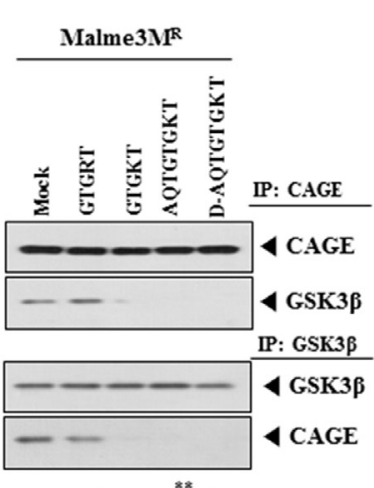

E Malme3M $M^{\mathrm{R}}$

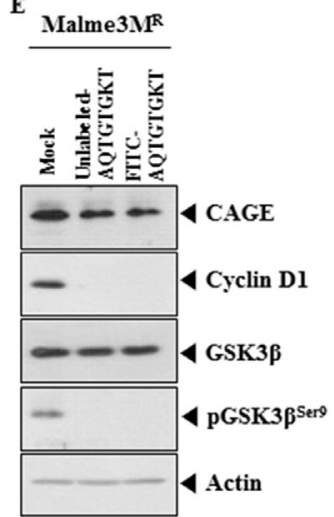

$\mathbf{F}$

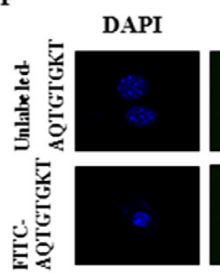

DAPI

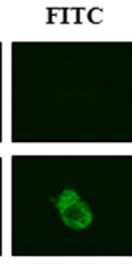

Merge

Malme $3 M^{\mathrm{R}}$

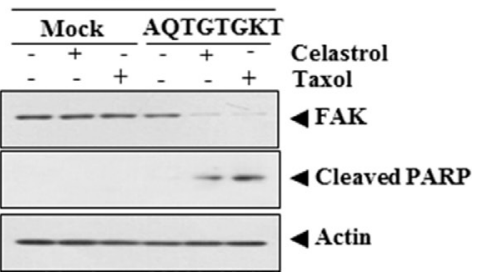

Figure 7: TGTGKT, QTGTGKT and AQTGTGKT peptides enhance apoptotic effects of anti-cancer drugs. (A) Malme $3 \mathrm{M}^{\mathrm{R}}$ cells were treated with the indicated peptide (each at $10 \mu \mathrm{M}$ ). At $48 \mathrm{~h}$ after treatment, cell lysates were subjected to Western blot analysis. Cell lysates were also immunoprecipitated with the indicated antibody $(2 \mu \mathrm{g} / \mathrm{ml})$, followed by Western blot analysis. A representative of at least two reproducible results is shown. (B) Malme $3 \mathrm{M}^{\mathrm{R}}$ cells were treated with the indicated peptide (each at $10 \mu \mathrm{M}$ ). At $48 \mathrm{~h}$ after treatment, immunoprecipitation employing the indicated antibody $(2 \mu \mathrm{g} / \mathrm{ml})$ was performed. (C) Malme $3 \mathrm{M}^{\mathrm{R}}$ cells were treated with the indicated peptide (each at $10 \mu \mathrm{M})$. At $24 \mathrm{~h}$ after treatment, cells were then treated with celastrol $(1 \mu \mathrm{M})$ or taxol $(1 \mu \mathrm{M})$ for $24 \mathrm{~h}$, followed by caspase-3 activity assays. ${ }^{* *} p<0.005$. (D) Malme $3 \mathrm{M}^{\mathrm{R}}$ cells were treated with TGTGKT, QTGTGKT or AQTGTGKT peptide $($ each at $10 \mu \mathrm{M})$. At $24 \mathrm{~h}$ after treatment, cells were then treated with celastrol $(1 \mu \mathrm{M})$ or taxol $(1 \mu \mathrm{M})$ for $24 \mathrm{~h}$, followed by caspase-3 activity assays. (E) Malme $3 \mathrm{M}^{\mathrm{R}}$ cells were treated with the indicated peptide (each at $10 \mu \mathrm{M}$ ). At $48 \mathrm{~h}$ after treatment, cell lysates were subjected to Western blot analysis. (F) FITC-labeled AQTGTGKT peptide $(10 \mu \mathrm{M})$ or AQTGTGKT peptide $(10 \mu \mathrm{M})$ was added to Malme3M ${ }^{\mathrm{R}}$ cells. At $48 \mathrm{~h}$ after transfection, the expression of FITC-labeled AQTGTGKT peptide was determined. 
shows the binding site for HDAC2 (Supplementary Figure 3A). GTGKT peptide prevents HDAC2 from binding to the promoter sequences of cyclinD1 (Figure 3E). It is therefore probable that CAGE, through binding to HDAC2, may regulate the expression of cyclinD1.

miR-200b suppresses cell migration by inhibiting PKC $\alpha$-Wnt 5 positive feedback loop [33]. Thus, CAGE may regulate $\mathrm{PKC} \alpha$-Wnt 5 positive feedback loop. It will be interesting to examine the effect of CAGE-miR200b feedback loop on PKC $\alpha$. In this study, we found an activation of $\mathrm{PKC} \alpha$ in $\mathrm{SNU} 387^{\mathrm{R}}$ cells and an activation of PKC $\delta$ in Malme $3 \mathrm{M}^{\mathrm{R}}$ cells (personal observations). It would be interesting to examine the effect of PKC $\alpha$ and PKC $\delta$ on GSK3 $\beta$ activity and the expression and phosphorylation of cyclinD1. It would be also interesting to examine the effect of CAGE-derived peptides on PKC activity.

EGFR (epidermal growth factor receptor) activation leads to the up-regulation of PI3K/Akt signaling and cyclinD1 [34]. EGFR activation increases the phosphorylation of $\beta$-catenin and the expression of pGSK $3 \beta^{\text {Ser9 }}$, resulting in a loss of $\beta$-catenin [35]. Malme $3 \mathrm{M}^{\mathrm{R}}$ cells show higher expression of $\mathrm{pEGFR}^{\mathrm{Y} 845}$ than Malme3M cells (personal observations). It is probable that CAGE activates EGFR signaling, which in turn increases the expression of pGSK3 $3 \beta^{\text {Serg }}$ and cyclinD1. CAGE confers resistance to various EGFR inhibitors (personal observations). This implies that EGFR signaling is involved in anti-cancer drug-resistance conferred by CAGE. It would be necessary to examine the effect of peptides corresponding to the DEAD box helicase domain of CAGE on EGFR signaling in Malme $3 \mathrm{M}^{\mathrm{R}}$ cells. It will also be interesting to examine the possibility of the binding of CAGE to EGFR.

SBPs (self-binding peptides) are short peptides within monomeric proteins and bind to target domains to perform biological functions. SBPs are generally found in disordered or unstructured regions of monomeric proteins. Many of those protein-protein interactions are regulated by short peptides such as SBPs [36, 37]. Peptide drugs disrupt protein-protein interfaces to regulate biological processes
A

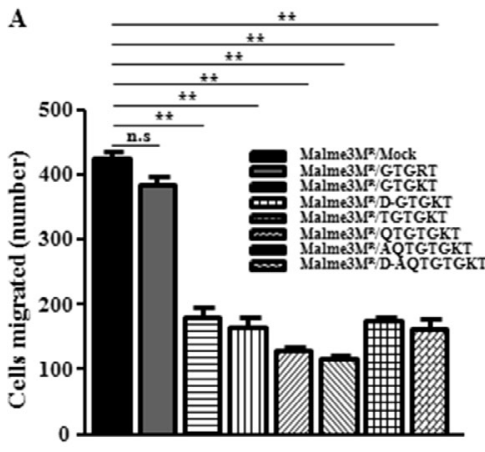

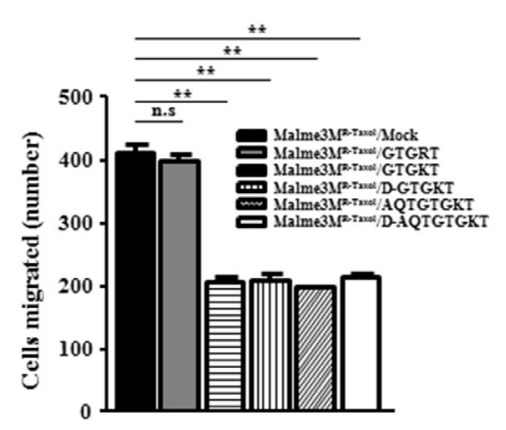

C

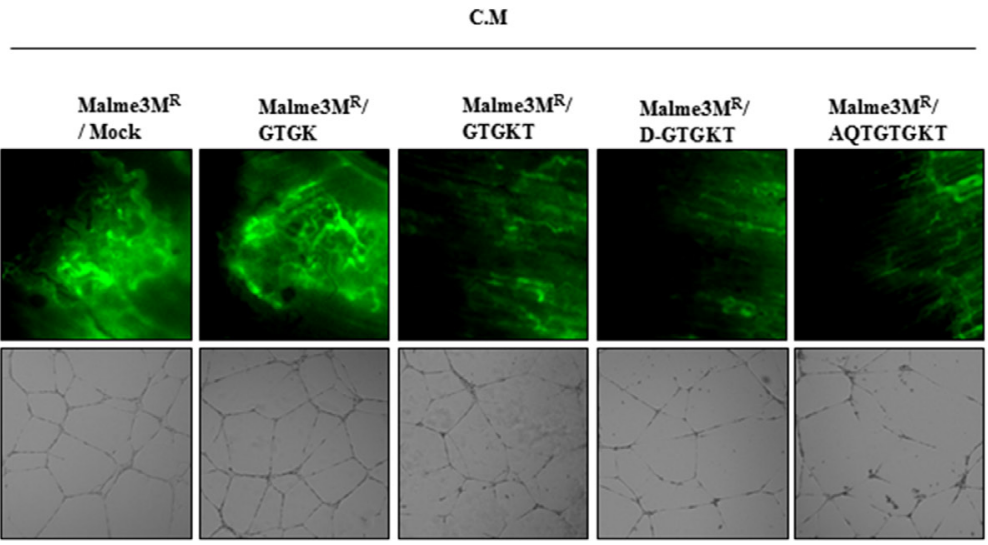

B
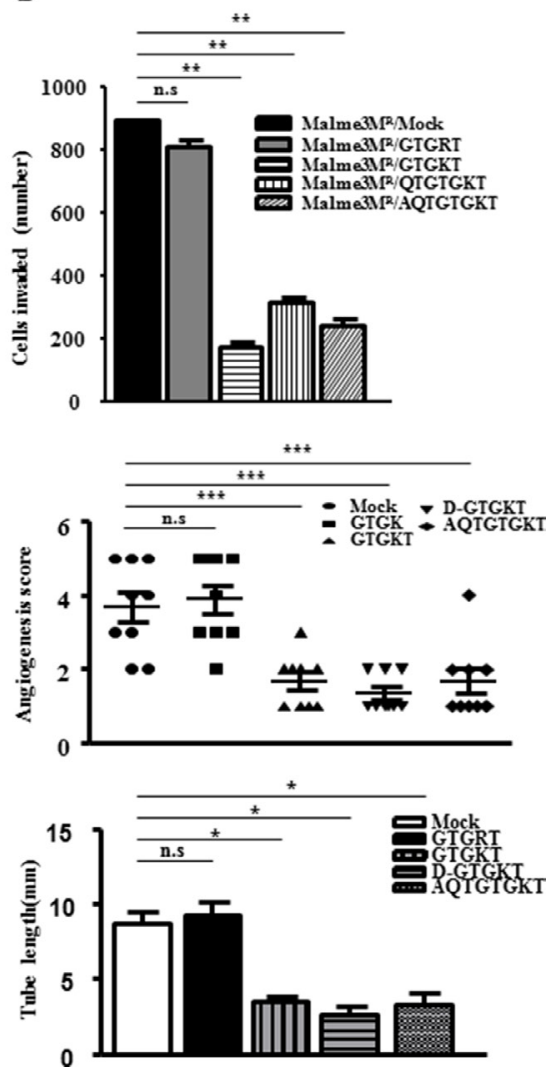

Figure 8: Peptides corresponding to the DEAD box helicase domain of CAGE decrease the migration, invasion and angiogenic potential of anti-cancer drug-resistant cancer cells. (A) A scratch was made on the cell layer with a micropipette tip and cultures were washed twice with serum-free medium. Cells were then treated with peptide of interest (each at $10 \mu \mathrm{M})$. Wound migration assays were performed as described. ${ }^{*} p<0.005$. N.S. denotes not significant. (B) Malme $3 \mathrm{M}^{\mathrm{R}}$ cells were treated with the indicated peptide (each at $10 \mu \mathrm{M}$ ). At $48 \mathrm{~h}$ after treatment, transwell invasion assays were performed as described. ** $p<0.005$. (C) Conditioned medium (C.M.) obtained from the Malme $3 \mathrm{M}^{\mathrm{R}}$ cells treated with the indicated peptide (each at $10 \mu \mathrm{M}$ ) was added to HUVECs. Eight hours after the addition of conditioned medium, intravital microscopy was performed as described (upper panel). The conditioned medium was also subjected to endothelial cell tube formation assays (lower panel). ${ }^{*} p<0.05 ; * * *<0.0005$. 
[38)]. ${ }^{100}$ RRNQYWV ${ }^{106}$ of c-Src serves as SBP and binds to PDZ5 domain of c-Src [39]. Given the fact that GTGKT peptide binds to CAGE, it is probable that GTGKT peptide can be considered as self-binding peptide (SBP). Given the fact that CAGE binds to GSK3 $\beta$ (Figure 1B), it is therefore reasonable that GTGKT peptide inhibits the binding of CAGE to GSK3 $\beta$. GTGKT peptide binds to c-terminal domain of CAGE (Supplementary Figure 5A). It would be necessary to identify critical amino acids of CAGE that are necessary for binding to GTGKT peptide.

Anti-tumor peptides inhibit oncogenesis by binding to and inhibiting oncogenes with aberrant expression in cancer cells. For example, WT1 (Wilms tumor protein 1)-derived peptide binds to p53 and inhibits the binding of WT1 to p53 and enhances cellular senescence and decreases the metastatic potential of human melanoma cells [40]. Anti-tumor peptides induce apoptosis, block signaling mediators and receptors, and inhibit angiogenesis and the metastasis [41, 42]. GTGKT peptide displays tumor homing potential (Figure 11). PHSCNK peptide, a novel tumor homing peptide, acts as an antagonist of integrin $\alpha_{5} \beta_{1}$ and suppresses melanoma [43]. CREKA peptide binds to fibrin and displays tumor homing potential [44]. It would be necessary to further identify receptor(s) of GTGKT peptide for better understanding of the mechanism of anti-cancer drug-resistance conferred by CAGE.

In this study, we show that peptides corresponding to the DEAD box helicase domain of CAGE can be developed as anti-cancer drugs for the treatment of cancer patients expressing CAGE.
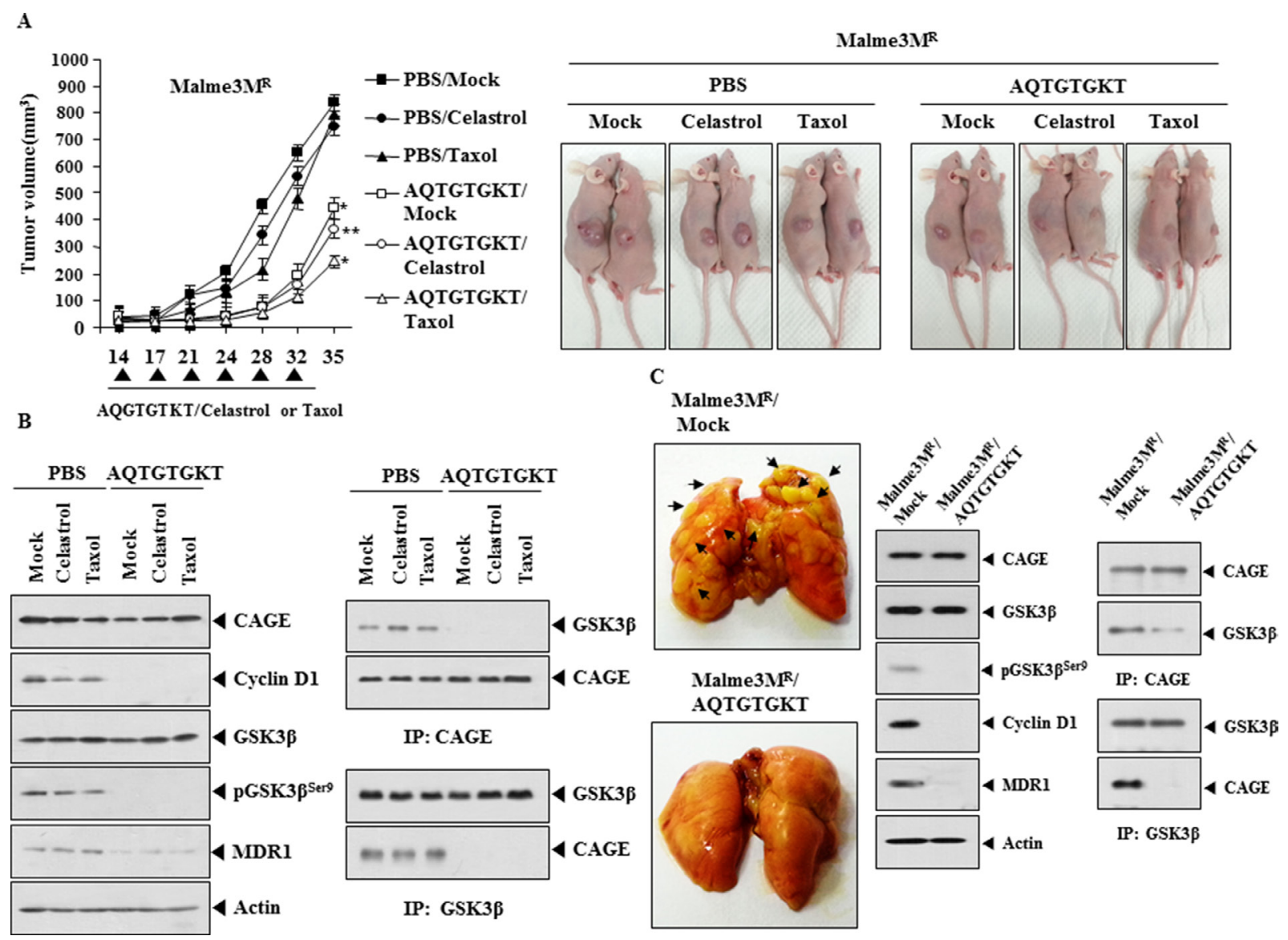

Figure 9: AQTGTGKT peptide decreases the tumorigenic and metastatic potential of anti-cancer drug-resistant cancer cells. (A) Malme $3 \mathrm{M}^{\mathrm{R}}\left(1 \times 10^{6}\right)$ cells were injected into the dorsal flanks of athymic nude mice. Following the establishment of sizeable tumor, peptide $(50 \mu \mathrm{g} / \mathrm{mouse})$ was injected into the tail vein along with celastrol $(1 \mathrm{mg} / \mathrm{kg})$ or taxol $(1 \mathrm{mg} / \mathrm{kg}) \mathrm{six}$ times in a total of 35 days. Each experimental group consisted of five mice. Each value represents an average obtained from the five athymic nude mice of each group. Data are expressed as a mean \pm S .D. Each figure shows a representative image of the mice in each group at the time of sacrifice. Statistically significant differences with PBS group are marked as ${ }^{*} p<0.05$ and $* * p<0.005$, respectively. (B) Lysates from the indicated tumor tissues were subjected to Western blot analysis (left panel). Lysates were also immunoprecipitated with the indicated antibody $(2 \mu \mathrm{g} / \mathrm{ml})$, followed by Western blot analysis (right panel). (C) Each experimental group consists of five athymic nude mice. Each figure shows a representative image of the mice in each experimental group. AQTGTGKT peptide $(50 \mu \mathrm{g} / \mathrm{mouse})$ was intravenously injected five times over a total of 4 weeks. Tumor lysate from each mouse of the experimental group was immunoprecipitated with the indicated antibody $(2 \mu \mathrm{g} / \mathrm{ml})$, followed by Western blot analysis. 


\section{MATERIALS AND METHODS}

\section{Chemicals and reagents}

Chemicals used in this study were purchased from Sigma Chemical Company. Anti- mouse and antirabbit IgG-horse radish peroxidase conjugate antibody were purchased from Pierce Company (Rockford, IL). All other antibodies used in this study were purchased from Santa Cruz Company. Lipofectamine and PlusTM reagent for transfection were purchased from Invitrogen (San Diego, CA). Peptides used in this study were commercially synthesized by Peptron Company (Daejon, Koea). SiRNA kit was purchased from Ambion Company.
Oligonucleotides used in this study were commercially synthesized by Bioneer Company (Daejon, Korea).

\section{Cell lines and cell culture}

Cancer cell lines used in this study were cultured in Dulbecco's modified minimal essential medium (Invitrogen) supplemented with heat-inactivated $10 \%$ fetal bovine serum (Invitrogen) and antibiotics at $37^{\circ} \mathrm{C}$ in a humidified incubator with a mixture of $95 \%$ air and $5 \% \mathrm{CO} 2$. Anti-cancer drug-resistant cancer cell lines $\left(\mathrm{SNU} 387^{\mathrm{R}}\right.$ and Malme $3 \mathrm{M}^{\mathrm{R}}$ ) were established as described [6]. Malme $3 \mathrm{M}^{\mathrm{R}}$ and $\mathrm{SNU} 387^{\mathrm{R}}$ cell lines were established by stepwise addition of celastrol. Cells surviving drug
A

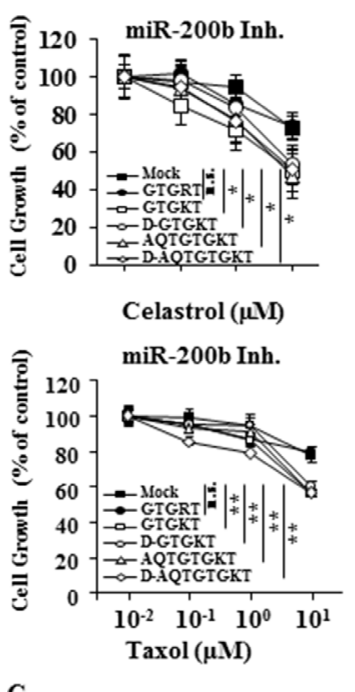

C
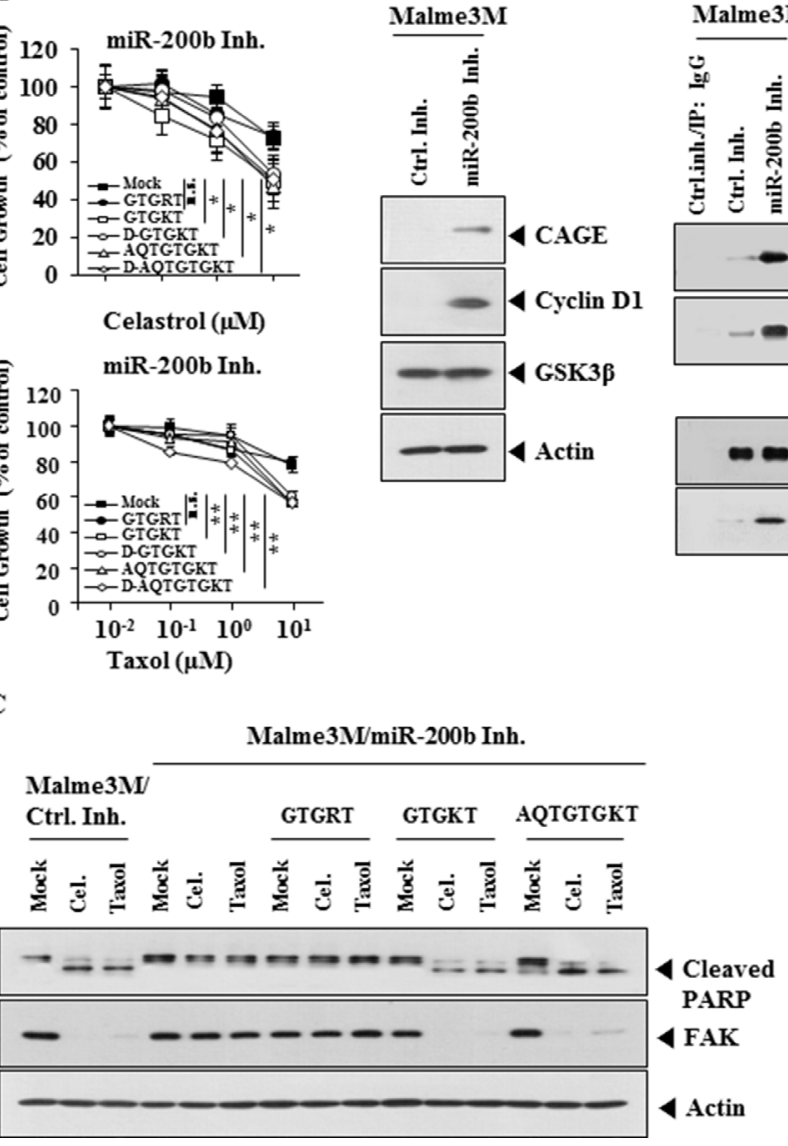

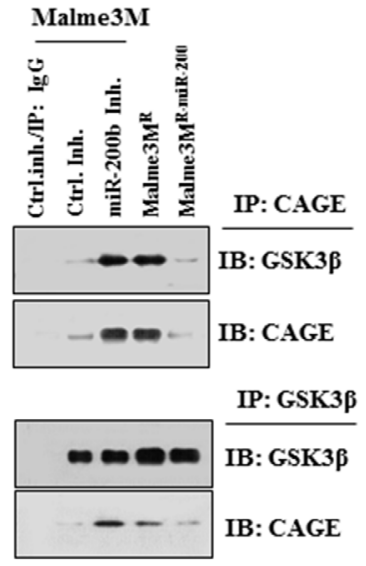

B
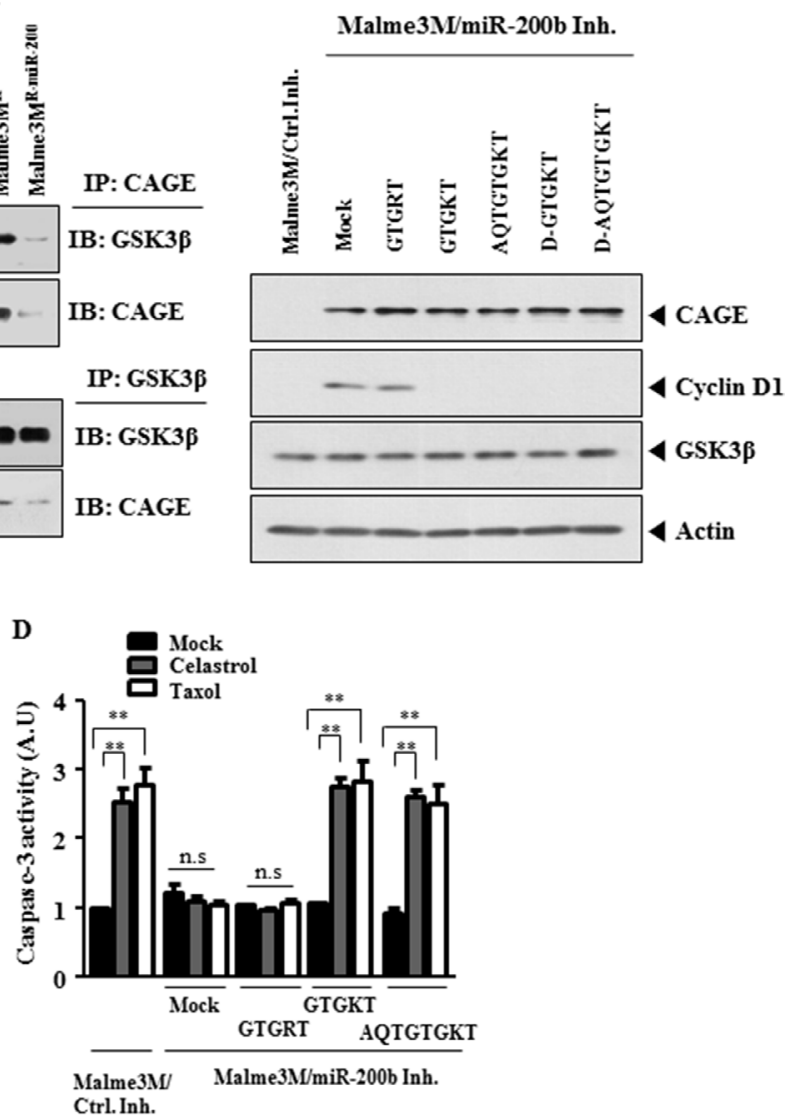

Figure 10: Peptides corresponding to the DEAD box helicase domain of CAGE enhance sensitivity to anti-cancer drugs in Malme3M cells transfected with miR-200b inhibitor. (A) Malme3M cells were transiently transfected with control inhibitor or miR-200b inhibitor (each at $50 \mathrm{nM}$ ). At $24 \mathrm{~h}$ after transfection, cells were treated with various concentrations of celastrol or taxol for $24 \mathrm{~h}$ along with the indicated peptide $(10 \mu \mathrm{M})$, followed by MTT assays (left panel). Statistically significant differences with mock control are marked as ${ }^{*} p<0.05,{ }^{* *} p<0.005$ and n.s., not significant, respectively. Malme3M cells were transiently transfected with the indicated inhibitor $(50 \mathrm{nM})$. At $48 \mathrm{~h}$ after transfection, cell lysates were subjected to Western blot analysis (middle panel). Cell lysates from Malme3M cells transfected with the indicated inhibitor (each at $50 \mathrm{nM}$ ) were immunoprecipitated with the indicated antibody $(2 \mu \mathrm{g} / \mathrm{ml})$ ), followed by Western blot analysis (right panel). Cell lysates from Malme $3 \mathrm{M}^{\mathrm{R}}$ or Malme $3 \mathrm{M}^{\mathrm{R}-\mathrm{miR}-200 \mathrm{~b}}$ were also immunoprecipitated with the indicated antibody $(2 \mu \mathrm{g} / \mathrm{ml}$ ), followed by Western blot analysis (right panel). (B) Malme3M cells were transiently transfected with the indicated inhibitor (each at $50 \mathrm{nM}$ ). At $24 \mathrm{~h}$ after transfection, cells were treated with the indicated peptide $(10 \mu \mathrm{M})$ for $24 \mathrm{~h}$, followed by Western blot analysis. (C) Malme3M cells were transiently transfected with control inhibitor or miR-200b inhibitor (each at $50 \mathrm{nM}$ ). At $24 \mathrm{~h}$ after transfection, cells were then transfected with celastrol $(1 \mu \mathrm{M})$ or taxol $(1 \mu \mathrm{M})$ along with each peptide (each at $10 \mu \mathrm{M})$ for $24 \mathrm{~h}$, followed by Western blot analysis. (D) Same as C except that caspase-3 activity assays were performed. ${ }^{* *} p<0.005$. 
treatment (attached fraction) were obtained and used throughout this study. Malme $3 \mathrm{M}^{\mathrm{R} \text {-taxol }}$ and SNU387 $7^{\mathrm{R}-\mathrm{Taxol}}$ cell lines were established by stepwise addition of taxol. Human umbilical vein endothelial cells (HUVECs) were isolated from human umbilical cord veins by collagenase treatment and used in passages 3-6. The cells were grown in M199 medium supplemented with $20 \%$ fetal bovine serum, 100 units $/ \mathrm{ml}$ penicillin $\mathrm{G}, 100 \mu \mathrm{g} / \mathrm{ml}$ streptomycin, $3 \mathrm{ng} / \mathrm{ml} \mathrm{bFGF}$ (Upstate Biotechnology, Waltham, MA), and 5 units $/ \mathrm{ml}$ heparin at $37{ }^{\circ} \mathrm{C}$ under $5 \% \mathrm{CO} 2,95 \%$ air.

\section{Mice}

All animal experiments were approved by Institutional Animal Care and Use Committee (IACUC) of Kangwon National University (KIACUC-14-0007).

\section{Peptides}

CAGE-derived peptides were synthesized by Peptron Company, with the sequences GTGK, AQTGTGKT, QTGTGKT, TGTGKT, GTGKT, GTGRT, GTGKA, GTGAT, D-GTGKT, D-AQTGTGKT, SQWAP, RNGPG and a purity level $>95 \%$. The FITC-conjugated GTGKT, FITCconjugated AQTGTGKT, and Biotin-GTGKT peptide were purified by high performance liquid chromatography and their sequence and structure were confirmed by mass spectrometry.

\section{Preparation of siRNA duplexes and transfection}

The siRNA duplexes were constructed with the following target sequences: CAGE, sense (5'-AACTCTGTCAACCTAAGAAGCCCTGTCTC-3'), and antisense (5'-AAGCTTCTTAGGTTGACAGAGCCT GTCTC-3'); CyclinD1, sense (5'-AACAGGTTCCACTT GAGCTTGCCTGTCTC 3'), and antisense (5'-AACAA GCTCAAGTGGAACCTGCCTGTCTC -3'); Scrambled CAGE, sense (5'-AA TTAATGATCGCCCAGAACC CCTGTCTC- 3'), and anti-sense (5'- AA GGTTCTGGG CGATCATTAA CCTGTCTC-3'); SP1, sense (5'-AAGAC TCAATTCTGCTGCAAGCCTGTCTC- $3^{\prime}$ ), and antisense (5'- AACTTGCAGCAGAATTGAGTCCCTGTCTC3' ); scrambled SP1, sense ((5'-AAAGTAAGGCCTACGAT TCCTCCTGTCTC- $3^{\prime}$ ), and anti-sense (5'-AAGCGTAC TATCGGCAATTGACCTGTCTC- 3'); Control, sense (5'-AATTCTCCGAACGTGTCACGTCCTGTCTC-3'), and antisense (5'-AAACGTGACACGTTCGGAGAAC CTGTCTC-3'). Control siRNA sequences were derived from green fluorescent protein sequences. The construction of siRNAs was performed according to the instruction manual provided by the manufacturer (Ambion, Austin, TX). Transfections were performed according to the manufacturer's instructions. Lipofectamine and Plus reagents (Invitrogen) were used. The construction of siRNA was carried out according to the instruction
A

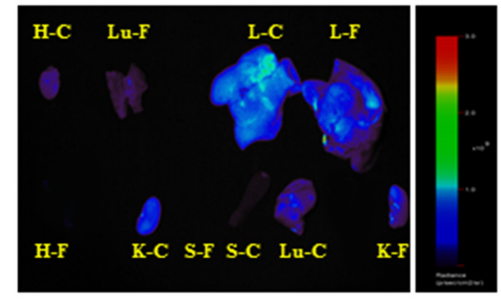

- K; Kidney - C ; Without FITC-GTGKT

- Lu ; Lung - F; With FITC-GTGKT

- $\mathrm{H} ;$ Heart

- L; Liver

- S; Spleen
B
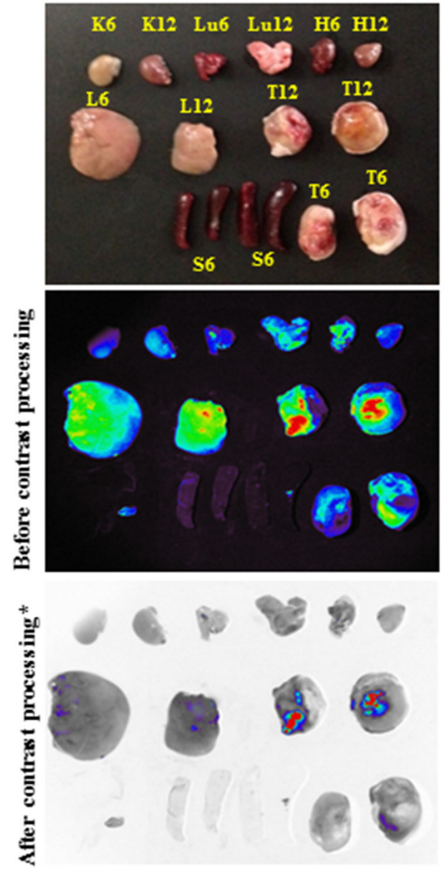

Tumor xenograft (Malme3MR)

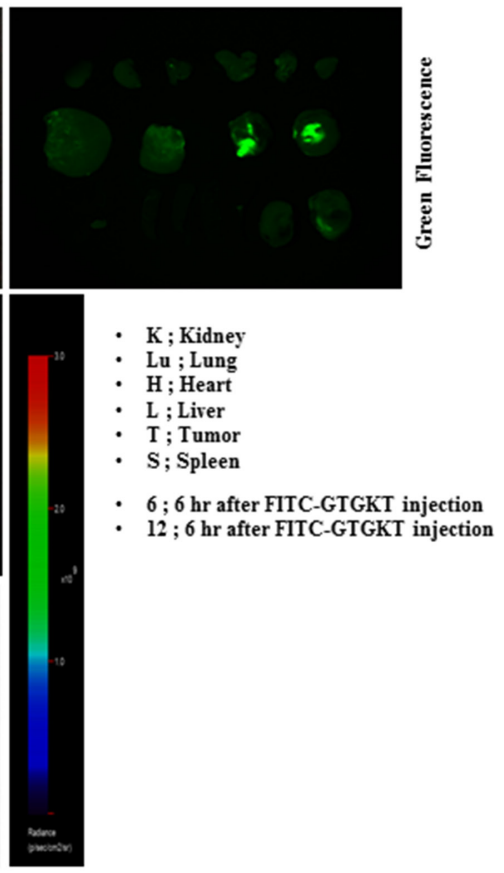

Figure 11: GTGKT peptide shows ex vivo tumor homing potential. Tumor-bearing nude mice (xenograft of Malme $3 \mathrm{M}^{\mathrm{R}}$ cells) were given intravenous injection of $50 \mu \mathrm{g}$ FITC-conjugated GTGKT peptide 4 weeks after Malme $3 \mathrm{M}^{\mathrm{R}}$ transplantation. Experimental and control mice were anesthetized and sacrificed 6 and $12 \mathrm{hrs}$ later and the abdominal wall was opened and tumor and normal organs analyzed by confocal microscopy. The representative distribution of FITC-conjugated GTGKT peptide at $12 \mathrm{hrs}$ after injection in dissected tumor and normal organs including kidney, liver, spleen, and lung is shown. Note the strong fluorescence accumulation in the tumor when compared to the control organs. 
manual provided by the manufacturer (Ambion, Austin, TX). For miR-200b knockdown, cells were transfected with $50 \mathrm{nM}$ of oligonucleotide (inhibitor) with Lipofectamine 2000 (Invitrogen), according to the manufacturer's protocol. The sequences used were 5'-UCAUCAUUACCCAGUAUUA-3' (miR-200b inhibitor) and 5'-GCAUAUAUCUAUUCCACUA-3' (control inhibitor).

\section{CAGE constructs}

Various CAGE deletion constructs were made by PCR amplification and cloning into Flag-tagged pcDNA3.1 vector. The full-length CAGE point mutant constructs were made by site-directed mutagenesis kit (Stratagene).

\section{Immunoprecipitation}

Cells $\left(1 \times 10^{7}\right)$ were lysed in immunoprecipitation buffer (50 mmol/liter HEPES, pH 7.6, $150 \mathrm{mmol} / \mathrm{liter}$ $\mathrm{NaCl}, 5 \mathrm{mmol} / \mathrm{liter}$ EDTA, 0.1\% Nonidet P-40). After centrifugation $(10 \mathrm{~min}$ at $15,000 \times \mathrm{g})$ to remove particulate material, the supernatant was incubated with each antibody (2 $\mu \mathrm{g} / \mathrm{ml}$ ) with constant agitation at $4^{\circ} \mathrm{C}$. The immune complexes were precipitated with protein $\mathrm{A} / \mathrm{G}-\mathrm{Sepharose}$ (Sigma) and analyzed by Western blot. To examine the effect of GTGKT peptide on the binding of CAGE to GSK3 $\beta$, biotin-GTGKT peptide (Peptron, Daejeon, Korea) was transfected with Lipofectamin and PlusTM reagent (Invitrogen, San Diego, CA). After incubation for $48 \mathrm{~h}$, whole-cell extracts were incubated with anti-biotin antibody $(2 \mu \mathrm{g} / \mathrm{ml})$ for $12 \mathrm{~h}$ at $4{ }^{\circ} \mathrm{C}$ and immune complexes were precipitated with streptavidin-linked agarose beads for $30 \mathrm{~min}$ at $4^{\circ} \mathrm{C}$. After five washes with lysis buffer, the bound proteins were eluted by boiling in $2 \mathrm{X}$ Laemli SDS loading buffer and were then subjected to SDS-PAGE followed by Western blotting analysis with anti-CAGE antibody.

\section{Western blot analysis}

Western blot analysis was performed according to the standard procedures [8]. For analysis of proteins from tumor tissues, frozen samples were grounded to a fine powder using a mortar and pestle over liquid nitrogen. Proteins were solubilized in RIPA buffer containing protease inhibitors and insoluble material removed by centrifugation.

\section{Cell viability determination}

The cells were assayed for their growth activity using the 3-(4, 5-dimethylthiazol-2-yl)-2, 5-diphenyltetrazolium bromide (MTT; Sigma). Viable cell number counting was carried out by trypan blue exclusion assays. At least two separate experiments were performed in triplicate.

\section{Colony formation}

Cells were cultured at low density under treatment, and then colonies were stained with $0.01 \%$ crystal violet and counted.

\section{Caspase- 3 activity assays}

Caspase- 3 activity was measured according to the manufacturer's instructions (BioVision, Palo Alto, CA). Cells were lysed in 0.1 M HEPES buffer, $\mathrm{pH} 7.4$, containing $2 \mathrm{mM}$ dithiothreitol, $0.1 \%$ CHAPS, and 1\% sucrose. Cell lysates were incubated with a colorimetric substrate, $200 \mu \mathrm{M}$ Ac-DEVD- $p$-nitroanilide, for $30 \mathrm{~min}$ at $30^{\circ} \mathrm{C}$. The fluorescence was measured at $405 \mathrm{~nm}$ using a microtiter plate reader.

\section{Wound migration}

Cells were plated overnight to achieve a confluent layer in 24-well plates. A scratch was made on the cell layer with a micropipette tip and cultures were washed twice with serum-free medium. Cells were then transfected with peptide of interest. Wound healing was visualized by comparing photographs taken at the time of transfection and $48 \mathrm{~h}$ later.

\section{Chemo invasion assays}

The invasive potential was determined by using a transwell chamber system with 8 - $\mu \mathrm{m}$ pore polycarbonate filter inserts (CoSTAR, Acton, MA). The lower and upper sides of the filter were coated with gelatin and Matrigel, respectively. Trypsinized cells $\left(5 \times 10^{3}\right)$ in the serum-free RPMI 1640 medium containing $0.1 \%$ bovine serum albumin were added to each upper chamber of the transwell. RPMI 1640 medium supplemented with 10\% fetal bovine serum was placed in the lower chamber and cells were incubated at $37^{\circ} \mathrm{C}$ for $16 \mathrm{~h}$. The cells were fixed with methanol and the invaded cells were stained and counted. Results were analyzed for statistical significance using the Student's $t$ test. Differences were considered significant when $p<0.05$.

\section{Immunofluorescence staining}

Cells were seeded on $10-\mathrm{mm}$ coverslips at a density of $2 \times 10^{5}$ cells/35-mm plate. Twenty-four hours after plating, cells were washed and fixed with $4 \%$ paraformaldehyde for $15 \mathrm{~min}$ at room temperature, and rinsed with cold PBS ( $\mathrm{pH}$ 7.4). After blocking with goat serum $(10 \%)$ in $0.1 \% \mathrm{BSA} / \mathrm{PBS}$, primary antibodies to CAGE (Santa Cruz, 1:100), GSK3 $\beta$ (Santa Cruz, 1:100), pGSK3 $\beta^{\text {Ser9 }}$ (Santa Cruz, 1:100), SP1 (Santa Cruz, 1:100), and phospho-cyclinD1 ${ }^{\text {Thr286 }}$ (Cell signaling Technology, $1: 200)$ were added and cells were incubated at $4^{\circ} \mathrm{C}$ for 
24 hour. After washing with PBS, slides were incubated with anti-rabbit Alexa Fluor 488 (for pcyclin $\mathrm{D}^{\text {Thr286}}$ ), anti-mouse Alexa Fluor 488 (for CAGE), or anti-goat Alexa Fluor 568 (pGSK3 $\beta^{\text {Ser9 }}$, GSK3 $\beta$, SP1) secondary antibodies for 1.5 hours at RT. After removal of antibodies, cells were washed with PBS and stained with DAPI and mounted with mounting medium. Fluorescence staining was visualized using confocal microscopy.

\section{Internalization experiments}

We used confocal microscopy to evaluate whether the FITC-conjugated-GTGKT and FITC-AQTGTGKT peptides were able to internalize. Briefly, Malme $3 \mathrm{M}^{\mathrm{R}}$ cells $\left(3 \times 10^{5}\right)$ cells were seeded in $35 \mathrm{~mm}$ culture dishes. After 24 hours of incubation, medium was replaced by fresh medium and FITC-conjugated GTGKT peptide (10 $\mu \mathrm{M})$ or FITC-conjugated AQTGTGKT peptide $(10 \mu \mathrm{M})$ was added to the cells. The FITC- GTGKT or FITC-AQTGTGKT peptide was incubated with the tumor cells for various time intervals. The medium was then removed and the cells were washed with $1 \mathrm{ml}$ PBS before being analyzed by confocal imaging on an inverted microscope with a confocal laser scanning unit. Unlabeled GTGKT peptide or AQTGTGKT peptide was employed as negative control to determine auto fluorescence of tumor cells. Processed serial sections were constructed into three-dimensional images using VoxelView (Vital Images Ltd., Fairfield, IA) on a Silicon Graphics Indy workstation (Mountain View, CA).

\section{Chromatin immunoprecipitation assays (ChIP)}

Assays were performed according to manufacturer's instruction (Upstate). For detection of the binding of protein of interest to cyclinD1 promoter sequences, specific primers of cyclinD1 promoter-1 sequences [5'-CCCAACTGCACCCCCTCCCT -3' (sense) and 5'-AGCCCCCTCACGCTCACGAA -3' (antisense)], cyclinD1 promoter-2 sequences [5'- GACCGGGCACAC AACCCCTG -3' (sense) and 5'- CAGTTGGGGACCCC CGCAAG -3' (antisense)] and cyclinD1 promoter-3 sequences [5'- TTGCAGCTCGCCGTGCTCTC-3' (sense) and 5'-GTGCCAGGGGCACCCCAATG -3' (antisense)] were used.

\section{Intravital microscopy}

Male BALB/c mice (6-8 week old) were obtained from Daehan Biolink (Korea). In vivo angiogenesis was assessed as follows. The mice were anesthetized with $2.5 \%$ avertin (v/v) via intraperitoneal injection (Surgivet, USA), and abdominal wall windows were implanted. Next, a titanium circular mount with eight holes on the edge was inserted between the skin and the abdominal wall. Growth factor-reduced matrigel containing the conditioned medium was applied to the space between the windows, and a circular glass cover slip was placed on top and fixed with a snap ring. After four days, the animals were anesthetized and injected intravenously with $50 \mu \mathrm{l}$ of $25 \mathrm{ng} / \mathrm{ml}$ fluorescein isothiocyanate-labeled dextran (molecular weight, $\mathrm{Mr} \sim 2,000,000$ ) via the tail vein. The mice were then placed on a Zeiss Axiovert 200 M microscope. The epi-illumination microscopy setup included a 100-W mercury lamp and filter set for blue light. Fluorescence images were recorded at random locations of each window using an electron-multiplying charge coupled device camera (Photo Max 512, Princeton Instruments, USA) and digitalized for subsequent analysis using the Metamorph program (Universal Imaging, USA). The assay was scored from 0 (negative) to 5 (most positive) in a double-blinded manner.

\section{Endothelial cell tube formation assays}

Growth factor-reduced matrigel was pipetted into pre-chilled 24-well plates (200 $\mu \mathrm{l}$ matrigel per well) and polymerized for $30 \mathrm{~min}$ at $37^{\circ} \mathrm{C}$. The HUVECs were placed onto the layer of matrigel in $1 \mathrm{ml}$ of M199 containing $1 \% \mathrm{FBS}$. After 6 to $8 \mathrm{~h}$ of incubation at $37^{\circ} \mathrm{C}$ in a $95 \%: 5 \%(\mathrm{v} / \mathrm{v})$ mixture of air and $\mathrm{CO}_{2}$, the endothelial cells were photographed using an inverted microscope (magnification, X100; Olympus). Tube formation was observed using an inverted phase contrast microscope. Images were captured with a video graphic system. The degree of tube formation was quantified by measuring the length of tubes in five randomly chosen low-power fields $(\times 100)$ from each well using the Image-Pro plus v4.5 (Media Cybernetics, San Diego, CA, USA).

\section{In vivo tumorigenic potential}

Athymic nude mice (BALB/c nu/nu, 5-6-weekold females) were obtained from Orient Bio Inc. (Seoul, Korea) and were maintained in a laminar air-flow cabinet under aseptic conditions. Cancer cells $\left(1 \times 10^{6}\right)$ of interest were injected subcutaneously into the dorsal flank area of the mice. Tumor volume was determined by direct measurement with calipers and calculated by the following formula: length $\times$ width $\times$ height $\times 0.5$. To determine the effect of peptides corresponding to the DEAD box helicase domain of CAGE on the tumorigenic potential, each peptide $(10 \mu \mathrm{g} / \mathrm{mouse}, 50 \mu \mathrm{g} / \mathrm{mouse}$, or $0.6 \mathrm{mg} / \mathrm{kg}$, $3 \mathrm{mg} / \mathrm{kg}$ ) was injected via tail vein five times in a total of 35 days or four times in a total of 35 days. To determine the effect of CAGE on the tumorigenic potential and in vivo anti-cancer drug-resistance, taxol (1 mg/kg) was injected, following the establishment of sizable tumor by injection of Malme $3 \mathrm{M}^{\mathrm{R} \text {-As-CAGE }}$ cells $\left(1 \times 10^{6}\right)$ or Malme $3 \mathrm{M}^{\mathrm{R} \text {-Vector }}$ cells, via tail vein four times in a total of 30 days. 


\section{In vivo metastasis assay}

Female athymic nude mice were used for the studies. Malme $3 \mathrm{M}^{\mathrm{R}}$ cells $\left(1 \times 10^{6}\right.$ cells in PBS $)$ were injected intravenously into the tail vein of 4-week-old athymic nude mice, and the extent of lung metastasis was evaluated. Peptide ( $50 \mu \mathrm{g} /$ mouse) of interests was injected intravenously into the tail vein of athymic nude mice five times. Four weeks after injection of cancer cells, surface metastatic nodules per lung were determined.

\section{Ex vivo homing assays}

Athymic nude mice (BALB/c nu/nu, 5-6-weekold females) were obtained from Orient Bio Inc. (Seoul, Korea) and were maintained in a laminar airflow cabinet under aseptic conditions. Malme $3 \mathrm{M}^{\mathrm{R}}$ cells $\left(1 \times 10^{6}\right)$ were injected subcutaneously into the dorsal flank area of the mice. Four-weeks after the injection of Malme $3 \mathrm{M}^{\mathrm{R}}$ cells, tumor bearing mice were given intravenous injection of $50 \mu \mathrm{g}$ FITC-GTGKT peptide. FITC-GTGKT peptide was allowed to circulate for 6 and 12 hours. In some experiments mice were perfused at the time of sacrifice with PBS through the left ventricle to remove blood and unbound peptide. Tumors and control organs were excised after the injection of the fluorescent peptide and examined for fluorescence using a versatile bio-imaging system (Davinch-In vivo Imaging System; Davinch-K, Seoul, Korea). Images were acquired using Davinch in vivo imaging system with excitation at $490 \mathrm{~nm}$ and the emitted fluorescence was collected through a longpass filter $(520 \mathrm{~nm})$. Data were analyzed by Davinch In vivo software (Davinch-K, Seoul, Korea).

\section{Statistical analysis}

Statistical differences in this were determined by using the Student's $t$ test. $P \leq 0.05$ was considered statistically significant.

\section{ACKNOWLEDGMENTS AND FUNDING}

This work was supported by National Research Foundation Grants (2014R1A2A2A01002448, 2015R1A 1A3A04001339, 2015R1A2A1A15051678 and 2016R1 A6A3A01006416), a grant from the BK21 plus Program, and grants from Kangwon National University (120150086 and 520160302).

\section{CONFLICTS OF INTEREST}

The authors declare no conflicts of interest.

\section{REFERENCES}

1. Cho B, Lim Y, Lee DY, Park SY, Lee H, Kim WH, Yang H, Bang YJ, Jeoung DI. Identification and characterization of a novel cancer/testis antigen gene CAGE. Biochem Biophys Res Commun. 2002; 292:715-726.

2. Iwata $\mathrm{T}$, Fujita $\mathrm{T}$, Hirao $\mathrm{N}$, Matsuzaki Y, Okada $\mathrm{T}$, Mochimaru H, Susumu N, Matsumoto E, Sugano K, Yamashita N, Nozawa S, Kawakami Y. Frequent immune responses to a cancer/testis antigen, CAGE, in patients with microsatellite instability-positive endometrial cancer. Clin Cancer Res. 2005; 11:3949-3957.

3. Cho B, Lee H, Jeong S, Bang YJ, Lee HJ, Hwang KS, Kim HY, Lee YS, Kang GH, Jeoung DI. Promoter hypomethylation of a novel cancer/testis antigen gene CAGE is correlated with its aberrant expression and is seen in premalignant stage of gastric carcinoma. Biochem Biophys Res Commun. 2003; 307:52-63.

4. Shim H, Shim E, Lee H, Hahn J, Kang D, Lee YS, Jeoung D. CAGE, a novel cancer/testis antigen gene, promotes cell motility by activation ERK and p38 MAPK and downmedoiat ROS. Mol Cells. 2006; 21:367-375.

5. Por E, Byun HJ, Lee EJ, Lim JH, Jung SY, Park I, Kim YM, Jeoung DI, Lee H. The cancer/testis antigen CAGE with oncogenic potential stimulates cell proliferation by upregulating cyclins D1 and E in an AP-1- and E2F-dependent manner. J Biol Chem .2010; 285:14475-14485.

6. Kim Y, Park H, Park D, Lee YS, Choe J, Hahn JH, Lee H, Kim YM, Jeoung D. Cancer/testis antigen CAGE exerts negative regulation on $\mathrm{p} 53$ expression through HDAC2 and confers resistance to anti-cancer drugs. J Biol Chem. 2010; 285:25957-25968.

7. Yao CX, Wei QX, Zhang YY, Wang WP, Xue LX, Yang F, Zhang SF, Xiong CJ, Li WY, Wei ZR, Zou Y, Zang MX. miR-200b targets GATA-4 during cell growth and differentiation. RNA Biol. 2013; 10:465-480.

8. Kim Y, Park D, Kim H, Choi M, Lee H, Lee YS, Choe J, Kim YM, Jeoung D. miR-200b and cancer/testis antigen CAGE form a feedback loop to regulate the invasion and tumorigenic and angiogenic responses of a cancer cell line to microtubule-targeting drugs. J Biol Chem. 2013; 288: 36502-36518.

9. Kim SJ, Lim JY, Lee JN, Choe SK, Kim YI, Song SR, Cho M, So HS, Park R. Activation of $\beta$-catenin by inhibitors of glycogen synthase kinase-3 ameliorates cisplatin-induced cytotoxicity and pro-inflammatory cytokine expression in HEI-OC1 cells. Toxicology. 2014; 320:74-82.

10. Zhang M, Zhang J, Chen X, Cho SJ, Chen X. Glycogen synthase kinase 3 promotes p53 mRNA translation via phosphorylation of RNPC1. Genes Dev. 2013; 27:2246-2258.

11. Takahashi RU, Takeshita F, Honma K, Ono M, Kato K, Ochiya T. Ribophorin II regulates breast tumor initiation and metastasis through the functional suppression of GSK3ß. Sci Rep. 2013; 3:2474.

12. Wang S, Li Y, Hsu PH, Lee SY, Kim Y, Lee EY. Progesterone receptor A stability is mediated by glycogen synthase kinase$3 \beta$ in the Brcal-deficient mammary gland. J Biol Chem. $2013 ; 288: 26265-26274$. 
13. Lee KH, Yoo CG. Simultaneous inactivation of GSK-3 $\beta$ suppresses quercetin-induced apoptosis by inhibiting the JNK pathway. Am J Physiol Lung Cell Mol Physiol. 2013; 304:782-789.

14. Lang UE, Kocabayoglu P, Cheng GZ, Ghiassi-Nejad Z, Muñoz U, Vetter D, Eckstein DA, Hannivoort RA, Walsh MJ, Friedman SL. GSK3 $\beta$ phosphorylation of the KLF6 tumor suppressor promotes its transactivation of $\mathrm{p} 21$. Oncogene. 2013; 32:4557-4564.

15. Thotala DK, Hallahan DE, Yazlovitskaya EM. Glycogen synthase kinase $3 \beta$ inhibitors protect hippocampal neurons from radiation-induced apoptosis by regulating MDM2-p53 pathway. Cell Death Differ. 2012; 19:387-396.

16. Takahashi-Yanaga F, Yoshihara T, Jingushi K, Igawa K, Tomooka K, Watanabe Y, Morimoto S, Nakatsu Y, Tsuzuki T, Nakabeppu Y, Sasaguri T. DIF-1 inhibits tumor growth in vivo reducing phosphorylation of GSK-3 $\beta$ and expressions of cyclin D1 and TCF7L2 in cancer model mice. Biochem Pharmacol. 2014; 89:340-348.

17. Koo J, Yue P, Gal AA, Khuri FR, Sun SY. Maintaining glycogen synthase kinase-3 activity is critical for mTOR kinase inhibitors to inhibit cancer cell growth. Cancer Res. 2014; 74:2555-2568.

18. Xu G, Li Y, Yoshimoto $\mathrm{K}, \mathrm{Wu} \mathrm{Q}$, Chen $\mathrm{G}$, Iwata T, Mizusawa N, Wan C, Nie X. 2,3,7,8-Tetrachlorodibenzop-dioxin stimulates proliferation of HAPI microglia by affecting the Akt/GSK-3 $\beta /$ cyclin D1 signaling pathway. Toxicol Lett. 2014; 224:362-370.

19. Natarajan V, Komarov AP, Ippolito T, Bonneau K, Chenchik AA, Gudkov AV. Peptides genetically selected for NF- $\kappa$ B activation cooperate with oncogene Ras and model carcinogenic role of inflammation. Proc Natl Acad Sci USA. 2014; 111:474-483.

20. Gu G, Gao X, Hu Q, Kang T, Liu Z, Jiang M, Miao D, Song Q, Yao L, Tu Y, Pang Z, Chen H, Jiang X, et al. The influence of the penetrating peptide iRGD on the effect of paclitaxel-loaded MT1-AF7p-conjugated nanoparticles on glioma cells. Biomaterials. 2013; 34:5138-5148.

21. Gallagher PE, Arter AL, Deng G, Tallant EA. Angiotensin-(1-7): a peptide hormone with anti-cancer activity. Curr Med Chem. 2014; 21:2417-2423.

22. Chang YW, Su CM, Su YH, Ho YS, Lai HH, Chen HA, Kuo ML, Hung WC, Chen YW, Wu CH, Chen PS, Su JL. Novel peptides suppress VEGFR-3 activity and antagonize VEGFR-3-mediated oncogenic effects. Oncotarget. 2014; 5:3823-3835. doi: 10.18632/oncotarget.1709.

23. Kim EH, Lee HJ, Lee DH, Bae S, Soh JW, Jeoung D, Kim J, Cho CK, Lee YJ, Lee YS. Inhibition of heat shock protein 27-mediated resistance to DNA damaging agents by a novel PKC delta-V5 heptapeptide. Cancer Res. 2007; 67:6333-6341.

24. Xu R, Povlsen GK, Soroka V, Bock E, Berezin V. A peptide antagonist of the ErbB1 receptor inhibits receptor activation, tumor cell growth and migration in vitro and xenograft tumor growth in vivo. Cell Oncol. 2010; 32:259-274.
25. Flügel D, Görlach A, Kietzmann T. GSK-3 $\beta$ regulates cell growth, migration, and angiogenesis via Fbw7 and USP28dependent degradation of HIF-1 $\alpha$. Blood. 2012; 119: 1292-1301.

26. Biliran H Jr, Wang Y, Banerjee S, Xu H, Heng H, Thakur A, Bollig A, Sarkar FH, Liao JD. Overexpression of cyclin D1 promotes tumor cell growth and confers resistance to cisplatin-mediated apoptosis in an elastase-myc transgeneexpressing pancreatic tumor cell line. Clin Cancer Res. 2005; 11:6075-6086.

27. Diehl JA, Cheng M. Roussel MF, Sherr CJ. Glycogen synthetase kinase-3b regulates cyclin D1proteolysis and subcellular localization. Genes Dev. 1998; 12:3499-3511.

28. Zou Y, Ewton DZ, Deng X, Mercer SE, Friedman E. Mirk/ dyrk1B Kinase Destabilizes Cyclin D1 by Phosphorylation at Threonine 288. J Biol Chem. 2004; 279:27790-27798.

29. Kim Y, Kim H, Park D, Jeoung D. miR-335 Targets SIAH2 and Confers Sensitivity to Anti-Cancer Drugs by Increasing the Expression of HDAC3. Mol Cells. 2015; 38:562-572.

30. Qiu T, Zhou X, Wang J, Du Y, Xu J, Huang Z, Zhu W, Shu Y, Liu P. MiR-145, miR-133a and miR-133b inhibit proliferation, migration, invasion and cell cycle progression via targeting transcription factor $\mathrm{Sp} 1$ in gastric cancer. FEBS Lett. 2014; 588:168-177.

31. Marampon F, Casimiro MC, Fu M, Powell MJ, Popov VM, Lindsay J, Zani BM, Ciccarelli C, Watanabe G, Lee RJ, Pestell RG. Nerve Growth factor regulation of cyclin D1 in PC12 cells through a p21RAS extracellular signal-regulated kinase pathway requires cooperative interactions between Sp1 and nuclear factor-kappaB. Mol Biol Cell. 2008; 19:2566-2578.

32. Noh JH, Jung KH, Kim JK, Eun JW, Bae HJ, Xie HJ, Chang YG, Kim MG, Park WS, Lee JY, Nam SW. Aberrant regulaton of HDAC2 mediates proliferation of hepatocellular carcinoma cells by deregulating expression of G1/S cell cycle proteins. PLoS One. 2011; 6:e28103.

33. Wang Z, Humphries B, Xiao H, Jiang Y, Yang C. MicroRNA-200b Suppresses Arsenic-transformed Cell Migration by Targeting Protein Kinase $\mathrm{C} \alpha$ and Wnt5bProtein Kinase C $\alpha$ Positive Feedback Loop and Inhibiting Rac1 Activation. J Biol Chem. 2014; 289:18373-18386.

34. Himaya SW, Dewapriya P, Kim SK. EGFR tyrosine kinase inhibitory peptide attenuates Helicobacter pylori-mediated hyper-proliferation in AGS enteric epithelial cells. Toxicol Appl Pharmacol. 2013; 269:205-214.

35. Lee CH, Hung HW, Hung PH, Shieh YS. Epidermal growth factor receptor regulates beta-catenin location, stability, and transcriptional activity in oral cancer. Mol Cancer. 2010; 9:64.

36. Petsalaki E, Stark A, García-Urdiales E, Russell RB. Accurate Prediction of Peptide Binding Sites on Protein Surfaces. PLoS Comput Biol. 2009; 5:e1000335.

37. Akiva E, Friedlander G, Itzhaki Z, Margalit HA. Dynamic View of Domain-Motif Interactions. PLoS Comput Biol. 2012; 8:e1002341. 
38. Verschueren E, Vanhee P, Rousseau F, Schymkowitz J, Serrano L. Protein-Peptide Complex Prediction through Fragment Interaction Patterns. Structure. 2013; 21:789-797.

39. Yang C, Zhang S, He P, Wang C, Huang J, Zhou P. Selfbinding peptides: folding or binding? J Chem Inf Model. 2015; 55:329-342.

40. Massaoka MH, Matsuo AL, Figueiredo CR, Girola N, Faria CF, Azevedo RA, Travassos LR. A novel cellpenetrating peptide derived from WT1 enhances p53 activity, induces cell senescence and displays antimelanoma activity in xeno- and syngeneic systems. FEBS Open Bio. 2014; 4:153-161.

41. Koskimaki JE, Lee E, Chen W, Rivera CG, Rosca EV, Pandey NB, Popel AS. Synergy between a collagen IV mimetic peptide and a somatotropin-domain derived peptide as angiogenesis and lymphangiogenesis inhibitors. Angiogenesis. 2013; 16:159-170.
42. Rosca EV, Koskimaki JE, Rivera CG, Pandey NB, Tamiz AP, Popel AS. Anti-angiogenic peptides for cancer therapeutics. Curr Pharm Biotechnol. 2011; 12:1101-1116.

43. Dai W, Yang T, Wang Y, Wang X, Wang J, Zhang X, Zhang Q. Peptide PHSCNK as an integrin $\alpha 5 \beta 1$ antagonist targets stealth liposomes to integrin-overexpressing melanoma. Nanomedicine. 2012; 8:1152-1161.

44. Chung EJ, Cheng Y, Morshed R, Nord K, Han Y, Wegscheid ML, Auffinger B, Wainwright DA, Lesniak MS, Tirrell MV. Fibrin-binding, peptide amphiphile micelles for targeting glioblastoma. Biomaterials. 2014; 35:1249-1256. 